ARTICLE

Received 26 Feb 2016 | Accepted 18 Mar 2016 | Published 25 Apr 2016

DOI: $10.1038 /$ ncomms11373

OPEN

\title{
Mechanical cell competition kills cells via induction of lethal p53 levels
}

\author{
Laura Wagstaff', Maja Goschorska1, Kasia Kozyrska', Guillaume Duclos², Iwo Kucinski ${ }^{1}$, Anatole Chessel $^{3, \dagger}$, \\ Lea Hampton-O'Neil ${ }^{1 \dagger}$, Charles R. Bradshaw ${ }^{1}$, George E. Allen ${ }^{1}$, Emma L. Rawlins ${ }^{1}$, Pascal Silberzan², \\ Rafael E. Carazo Salas ${ }^{3} \&$ Eugenia Piddini ${ }^{1}$
}

Cell competition is a quality control mechanism that eliminates unfit cells. How cells compete is poorly understood, but it is generally accepted that molecular exchange between cells signals elimination of unfit cells. Here we report an orthogonal mechanism of cell competition, whereby cells compete through mechanical insults. We show that MDCK cells silenced for the polarity gene scribble $\left(s c r i b{ }^{K D}\right)$ are hypersensitive to compaction, that interaction with wild-type cells causes their compaction and that crowding is sufficient for scrib ${ }^{K D}$ cell elimination. Importantly, we show that elevation of the tumour suppressor p53 is necessary and sufficient for crowding hypersensitivity. Compaction, via activation of Rho-associated kinase (ROCK) and the stress kinase p38, leads to further p53 elevation, causing cell death. Thus, in addition to molecules, cells use mechanical means to compete. Given the involvement of p53, compaction hypersensitivity may be widespread among damaged cells and offers an additional route to eliminate unfit cells.

\footnotetext{
${ }^{1}$ The Wellcome Trust/Cancer Research UK Gurdon Institute and Zoology Department, University of Cambridge, Tennis Court Road, Cambridge CB2 1QN, UK.

${ }^{2}$ Laboratoire PhysicoChimie Curie, Institut Curie, Paris Sciences et Lettres Research University - Sorbonne Universités, Université Pierre et Marie Curie - Centre National de la recherche Scientifique - Equipe labellisée Ligue Contre le Cancer, 75005 Paris, France. ${ }^{3}$ Pharmacology Department, University of Cambridge, Tennis Court Road, Cambridge CB2 1PD, UK. † Present addresses: LOB, Ecole Polytechnique, CNRS, INSERM, Université Paris-Saclay, 91128 Palaiseau cedex, France (A.C.); Faculty of Medical and Veterinary Sciences, University of Bristol, Bristol BS8 1TD, UK (L.H.-O.). Correspondence and requests for materials should be addressed to E.P. (email: e.piddini@gurdon.cam.ac.uk).
} 
C ell competition is a remarkable phenomenon, conserved from arthropods to mammals, that causes the elimination of relatively less fit cells from tissues, helping to maintain overall tissue health ${ }^{1-10}$. Despite important advances ${ }^{11-16}$, the mechanisms that lead to the elimination of unfit cells are still little understood and it is unclear whether one or multiple pathways lead to cell killing ${ }^{17-22}$.

It has recently been reported that Madin-Darby canine kidney (MDCK) epithelial cells silenced for the polarity gene scribble $\left(s c r i b b^{K D}\right.$ cells) are eliminated in the presence of wild-type MDCK cells $^{23}$, while they are viable on their own $^{23}$. However, the mechanisms by which scrib ${ }^{K D}$ cells are killed by wild-type cells are largely unknown. We therefore took advantage of this recent observation to investigate the mechanisms of cell competition.

Here we show that $s c r i b{ }^{K D}$ cells are out-competed by wild-type cells through mechanical insults rather than molecular exchange. We find that $s c r i b^{K D}$ cells are hypersensitive to compaction and that this is due to elevation of baseline p53 levels, which is both necessary and sufficient to induce hypersensitivity to crowding and confer a mechanical loser status. We further show that on contact with wild-type cells, $s c r i b^{K D}$ cells become compacted into a high-density arrangement and that compaction is not only required but also sufficient to eliminate $s c r i b^{K D}$ cells. We also delineate the mechano-transduction cascade that leads to $s c r i b^{K D}$ cell death. Specifically, we show that $s c r i b^{K D}$ cells' compaction causes activation of the Rho-associated kinase (ROCK), which in turn activates p38 leading to further p53 elevation and cell death. Overall, this work demonstrates that mechanical forces can be responsible for the elimination of cells during cell competition and that p53 levels play a key role both in instructing the mechanical loser status and in the execution of mechanical cell competition.

\section{Results}

Compaction of $s c r i b^{K D}$ cells induces mechanical competition. It has previously been shown that $s c r i b^{K D}$ MDCK cells are eliminated when co-cultured with wild-type MDCK cells through cell death and delamination (see ref. 23 and Supplementary Fig. 1a and Supplementary Movie 1, left), while monocultures of scrib ${ }^{K D}$ cells are viable (see ref. 23 and Supplementary Fig. $1 \mathrm{~b}$ and Supplementary Movie 1, right). To investigate the mechanisms of $s c r i b{ }^{K D}$-mediated cell competition, we first asked whether it is mediated by soluble factors, as in other cases of in vitro cell competition $^{6,24}$. Growth rate (doubling time) profiles showed that $s c r i b{ }^{K D}$ cells in pure cultures divide, albeit at a reduced rate, to reach a steadily maintained number (Supplementary Fig. 1d), whereas under competing conditions, their numbers collapse following initial growth (Fig. 1a). Interestingly, we found that the growth rate of $s c r i b^{K D}$ cells is not affected by conditioned medium from competing cultures (Fig. $1 \mathrm{~b}$ and Supplementary Fig. 1c). Similarly, in transwell systems that allow exchange of solutes but prevent cell contact, scrib ${ }^{K D}$ cells grown together with co-cultures of competing (wild-type/scrib ${ }^{K D}$ ) cells grew comparably to $s c r i b^{K D}$ cells grown with other $s c r i b{ }^{K D}$ cells (Fig. 1c and Supplementary Fig. 1c). This indicated that soluble factors are not sufficient to induce cell competition and that cell contact is required. We hypothesized that cell contact enables molecular interactions essential for cell competition, as observed by others ${ }^{11,12}$. However, to our surprise, we found that sustained contact with wild-type cells is not sufficient for elimination of $s c r i b^{K D}$ cells (Fig. 1d, black arrow and Supplementary Movie 2) and that $s c r i b{ }^{K D}$ clones are efficiently eliminated only when fully surrounded by wild-type cells (Fig. 1d, white arrow and Supplementary Movie 2). This suggested that a type of exchange other than molecular signalling (which would be enabled by contact) may be needed, and prompted us to look for differences between $s c r i b{ }^{K D}$ clones that were surrounded and peripheral clones that were simply contacted.

One striking feature of surrounded clones, which is not shared by peripheral clones, is that they reach a dramatically higher cell density than confluent $s c r i b^{K D}$ pure cultures (Fig. $1 \mathrm{e}-\mathrm{g}$ and Supplementary Fig. 1e). scrib ${ }^{K D}$ cells acquire a flattened morphology upon gene silencing 23,25 , which at confluence results in a much lower $(\sim 1 / 3)$ final density compared with wild-type cells (Fig. 1e-g). However, scrib ${ }^{K D}$ clones surrounded by wild-type cells do not flatten and reach a density that is $\sim 4.5$ fold higher than that of pure $s c r i b^{K D}$ cultures (Fig. 1e-g). Furthermore, competing $s c r i b{ }^{K D}$ cells are taller than when grown in single cultures (Fig. $1 \mathrm{~h}-\mathrm{j}$ ). Together, this indicates that as a result of their interaction with wild-type cells, scrib ${ }^{K D}$ cells become more compacted than in their default state and this correlates with and precedes their elimination.

We next asked whether cell compaction plays a role in $s c r i b{ }^{K D}$ cell elimination, by assessing its effect on $s c r i b^{K D}$ cells in complete absence of wild-type cells. To that end, we used micropatterns to form $s c r i b^{K D}$ microcultures of a defined, homogenous density and size ( $\varnothing=800 \mu \mathrm{m}$, ref. 26 ). When plated at high density, control cells that had not undergone scribble silencing (without tetracycline, - TET) continued to grow until they reached a maximal density of $61 \pm 4$ cells per $10,000 \mu \mathrm{m}^{2}$, which they maintained homeostatically (Fig. 1k,l and Supplementary Movie 3 , left), as previously shown ${ }^{27,28}$. Remarkably, $s c r i b^{K D}$ cultures $(+$ TET $)$ instead saw their numbers and densities drop (Fig. 1m,n, dark green and Supplementary Movie 3, right), due to a combination of increased cell death and extrusion, the same two events that lead to the elimination of $s c r i b{ }^{K D}$ cells during cell competition (Supplementary Movie 1, left and ref. 23). Notably, $s c r i b^{K D}$ cells seeded at a lower density maintained that initial density (Fig. 1n, light green) indicating that the drop in cell number observed at higher density is not a general response of $s c r i b{ }^{K D}$ cells to plating. This suggested that $s c r i b{ }^{K D}$ cells are hypersensitive to compaction. To test this directly, we seeded confluent monolayers of control ( $-\mathrm{TET})$ or $s c r i b{ }^{K D}(+\mathrm{TET})$ cells on stretched polydimethylsiloxane (PDMS) substrates, which we then released to induce cell compression ${ }^{27}$. Control cultures showed no increase in apoptosis upon compression (Fig. 1o-q). The $s c r i b{ }^{K D}$ cells, however, displayed a 3 -fold increase in apoptosis over their uncompressed baseline cell death, which was already higher than control (Fig. 1p,q). Altogether, these experiments show that $s c r i b^{K D}$ cells display hypersensitivity to cell density and cannot sustain levels of crowding normally reached by wild-type cells. They further indicate that compaction of $s c r i b^{K D}$ cells into higher cell densities, like those imposed on them by wild-type cells during competition, is sufficient to induce cell death. This suggests that wild-type cells eliminate $s c r i b^{K D}$ cells through crowding-induced compaction. We name this new mode of selective elimination of one cell population by another due to differential sensitivity to crowding 'mechanical cell competition', to contrast it with forms of cell competition that rely on molecular exchange.

Corralling promotes but is not needed for $s c r i b^{K D}$ elimination. As shown in Fig. 1f,g, in subconfluent competing cultures, the density of $s c r i b{ }^{K D}$ cells surpasses that of surrounding wild-type cells. This indicates that their acquired density does not simply reflect the density of the mixed culture, but is the result of an active process. To understand how $s c r i b^{K D}$ cells become compacted during competition, we plated cells at low density and observed what happens when wild-type and $s c r i b{ }^{K D}$ clones first come into contact. Strikingly, we saw that, on contact, both 

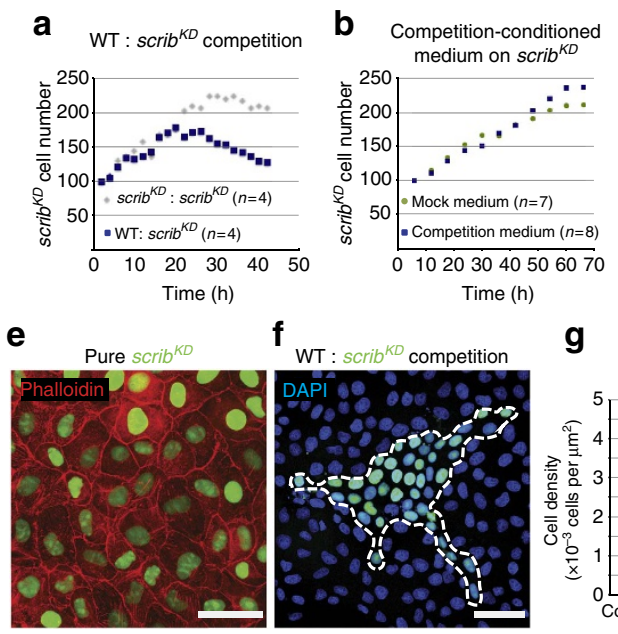

g
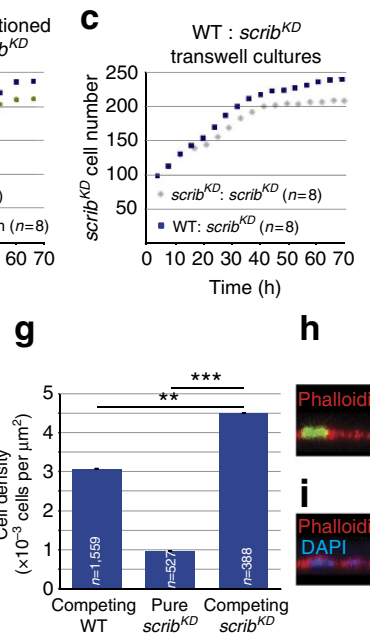

h

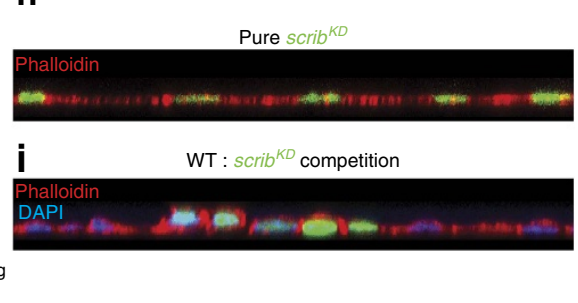

m
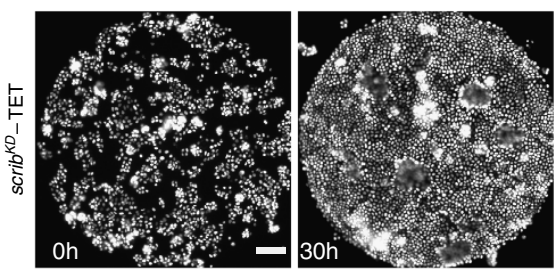

I
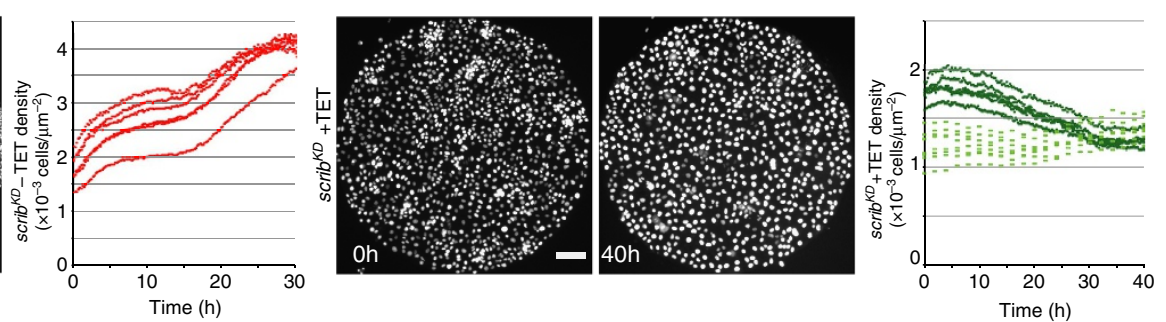

p
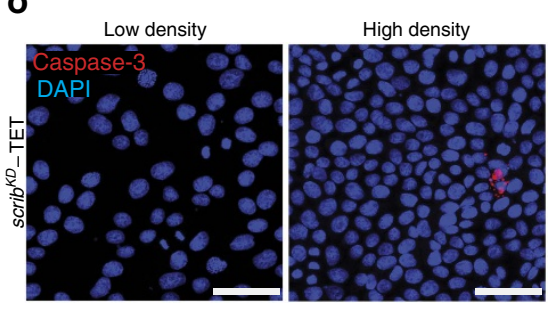

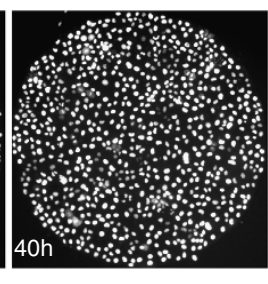

d
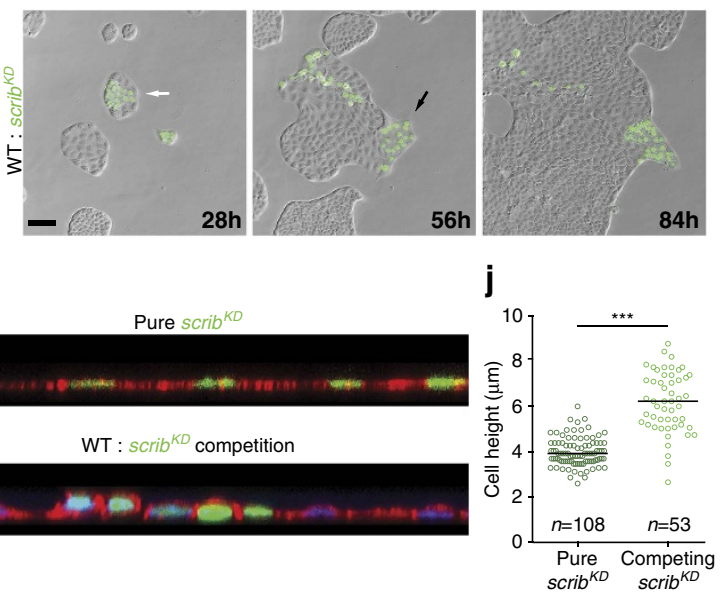

n

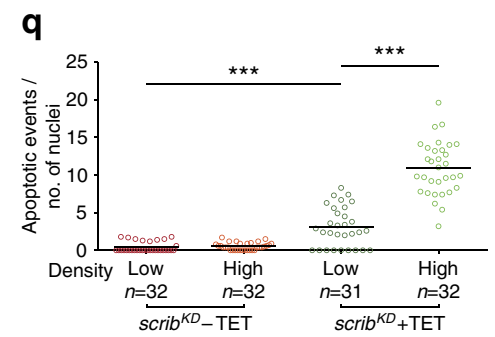

Figure 1 | Compaction of scrib ${ }^{K D}$ cells is both required and sufficient for their elimination. (a-c) Quantification showing growth rate of scrib ${ }^{K D}$ cells from time-lapse movies of: competition versus pure cultures (a), pure cultures in mock conditioned versus competition conditioned medium; two biological replicates (b) or transwell experiments, where scrib ${ }^{K D}$ cells were co-cultured across transwells with control or with competing cultures; three biological replicates (c). Each dot represents the average of $n$ fields of cells. See also Supplementary Fig. 1c. (d) Time course of cell competition assay between unlabelled wild-type (WT) and GFP-labelled scrib ${ }^{K D}$ MDCK cells. Competition is observed in surrounded scrib ${ }^{K D}$ cells (white arrow), but not in cells that are only contacted (black arrow), see corresponding Supplementary Movie 2. (e) Confluent GFP-labelled scrib ${ }^{K D}$ cells stained with phalloidin. (f) Competing unlabelled WT and GFP-labelled scrib ${ }^{K D}$ cells counterstained with DAPI. (g) Quantification showing average ( \pm s.e.m.) cell density values of confluent pure $s c r i b^{K D}$ cells and subconfluent competing WT and scrib ${ }^{K D}$ cells as in $\mathbf{e}$ and $\mathbf{f}$. (h,i) Confocal $x z$ sections of representative GFP-labelled scrib ${ }^{K D}$ cells pure (h) or co-cultured with WT cells (i), stained with phalloidin (h,i) and DAPI (i). (j) Quantifications of cell height from images as in $\mathbf{h}$ and $\mathbf{i}$. Black bars $=$ median. $(\mathbf{k}, \mathbf{m})$ Representative stills from time lapse of GFP-labelled scrib ${ }^{K D}$ cells $+/-$ TET growing on micropatterns $(800 \mu \mathrm{m} \varnothing)$, see corresponding

Supplementary Movie 3. (I,n) Quantifications of cell density over time from movies as in $\mathbf{k}$ and $\mathbf{m}$. Each dotted line corresponds to a different movie. (o,p) Cleaved Caspase-3 staining in WT (o) and scrib ${ }^{K D}(\mathbf{p})$ cells + / - compression (high density and low density, respectively). (q) Quantification of cell death events (cleaved Caspase-3) from images as in $\mathbf{0}$ and $\mathbf{p}$. Data are pooled from three biological replicates. Black bars = mean; three biological replicates across two independent experiments. $n=$ number of fields imaged in a single repeat $(\mathbf{a}-\mathbf{c}, \mathbf{q})$ or $n=$ number of cells $(\mathbf{g}, \mathbf{j})$. Scale bars, $100 \mu \mathrm{m}(\mathrm{movie}$ sequences) and $50 \mu \mathrm{m}$ (immunofluorescence images) here and throughout all figures. ${ }^{\star \star} P<0.005,{ }^{\star \star \star} P<0.0005$ by KS test.

scrib ${ }^{K D}$ and wild-type cells engage in collective cell migration (Fig. 2a and Supplementary Movie 4). This behaviour was specific to wild-type/scrib ${ }^{K D}$ encounters, as it was not observed upon homotypic encounters of either cell population (Fig. $2 \mathrm{~b}$ and Supplementary Movie 5). Interestingly, this migration was highly directional with $s c r i b^{K D}$ cells always at the migrating front and, conversely, wild-type cells always at the back. We next characterized this migratory behaviour and assessed its contribution to cell compaction and elimination. First, we repeated the above experiment using a fluorescent nuclear label in each population to facilitate cell tracking (Fig. 2c). Kymograph analysis showed rapid activation of collective cell migration at the time of contact between wild-type and scrib ${ }^{K D}$ cells, with both populations moving synchronously (Fig. 2d, top and Fig. 2e). By 
a

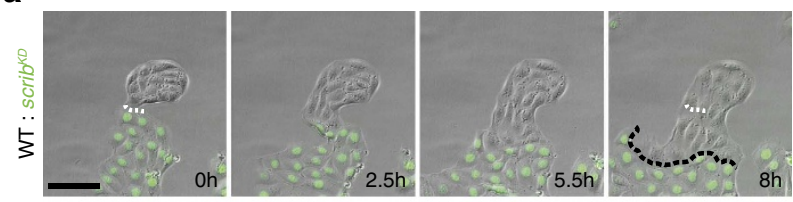

b

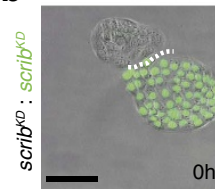

e

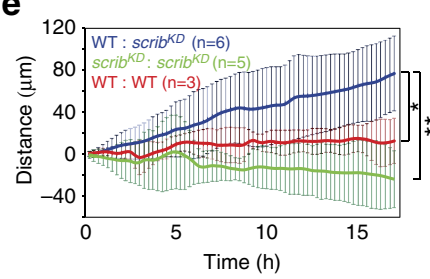

g

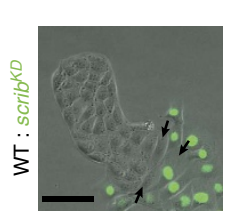

I

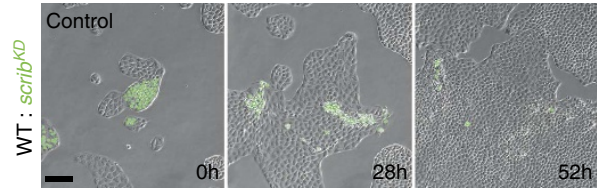

h

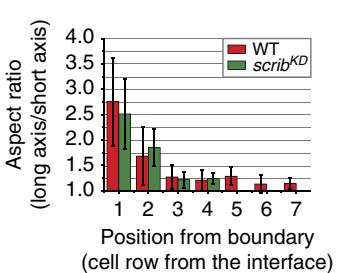

f

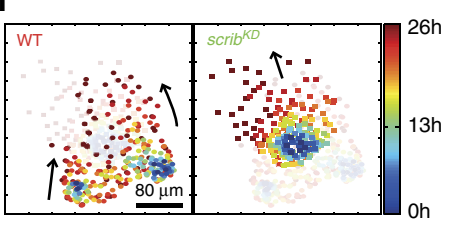

i Cell number j

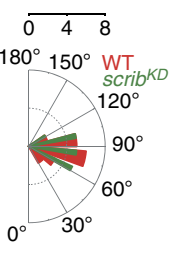

m

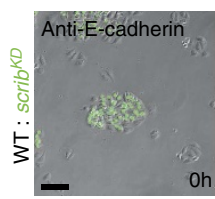

j
C

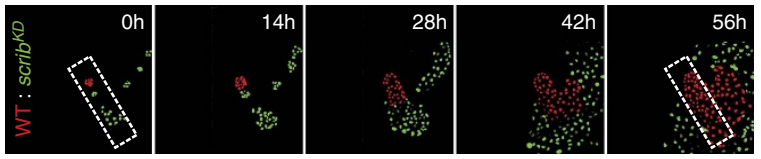

d

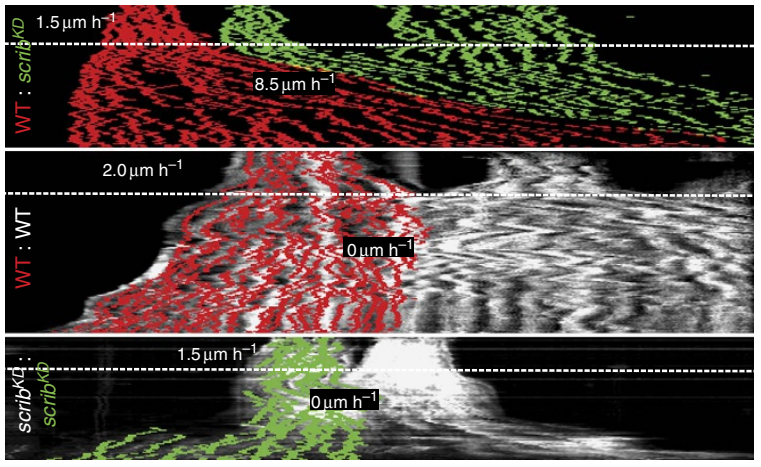

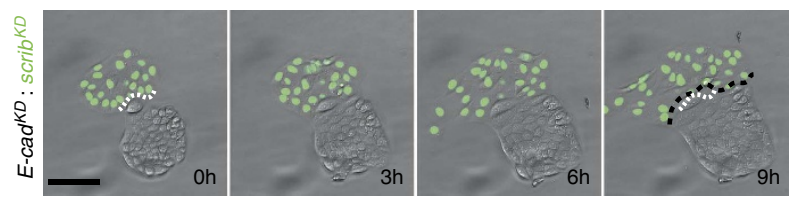
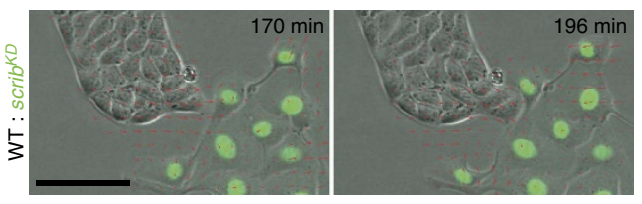

n

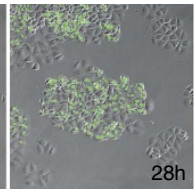

\section{n}

$\mathbf{q}$ $\mathbf{k}$

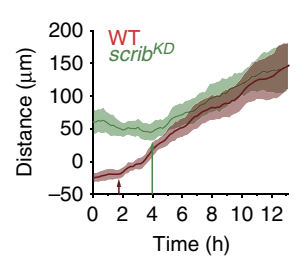

Figure 2 | Contact-induced migration promotes compaction and cell competition. (a,b) Stills from movies of wild-type (WT) and GFP-labelled scrib ${ }^{K D}$ cocultures (a) or scrib ${ }^{K D}$ homotypic cultures (b), see Supplementary Movie 4,5. (c,d) Kymographs (d) from movies as in c. Velocities are shown before (above dashed white line) and after contact (below line). (e) Plot showing displacement of the line of contact between clones from movies as in $\mathbf{c}$. The continuous line is the position of the front average \pm s.d.; $n=$ number of contact lines averaged. (f) Single-cell tracking of trajectories of WT and scrib ${ }^{K D}$ cells during competition. Heat-map representation shows time-resolved position of single cells. (g) Micrograph exemplifying cell shape change (arrows) after contact between WT and scrib ${ }^{K D}$ cells. (h) Bar plot representing aspect ratio of WT and scrib ${ }^{K D}$ cells as a function of distance from their contact point. $n=50$ cells of each type from three movies; error bars $=$ s.d. (i) Distribution of angles between a cell's long axis and its direction of motion; $n(W T)=18$ cells; $n$ $\left(s c r i b{ }^{K D}\right)=17$ cells. (j,k) PIV analysis of images at time of contact (see Supplementary Movie 6) (j); and quantification of cell displacements (k) shows WT cells begin migrating (arrows) before scrib ${ }^{K D}$ cells; $n=10$ cells for each type from three independent movies. Coloured lines $=$ mean; shaded areas $=\mathbf{s}$.d. (I-o) Disrupting cell junctions by E-cadherin blocking antibody and calcium removal prevents contact-induced migration (m), compaction (n) and delays competition (o) compared with control (I), see Supplementary Movie 8; error bars =s.e.m. (p) E-cadherin knockdown in WT cells $\left(E\right.$-cad $\left.{ }^{K D}\right)$ prevents contact-induced migration. (q) E-cadherin knockdown in scrib ${ }^{K D}$ cells (scrib ${ }^{K D} E$-cad ${ }^{K D}$ ) prevents contact-induced migration, see Supplementary Movie 9. Right panel displays anti-E-cadherin immunofluorescence at end of movie (see Supplementary Fig. 2h,i). Five independent repeats; $n=10$ events showing absence of directional migration, five were validated for E-cadherin levels and all five had WT levels. White dashed line =initial contact point; black dashed line = final contact point; yellow dashed line separates WT from scrib ${ }^{K D} E$-cad ${ }^{K D}$ cells. ${ }^{\star} P<0.05,{ }^{\star \star} P<0.005$ by $K S$ test.

contrast, similar kymographs of homotypic collisions did not show significant cell displacement (Fig. 2d, centre and bottom; and Fig. 2e). To further characterize the features of this collective cell migration, we carried out single-cell tracking of both cell populations before and after contact. The analysis of individual cell trajectories shows that single-cell movement is faster and more persistent for both wild-type and $s c r i b^{K D}$ cells upon heterotypic collision (Fig. $2 \mathrm{f}$ and Supplementary Fig. 2a-d). We 
then looked more closely at the dynamic interplay between wildtype and $s c r i b^{K D}$ cells at the onset of migration. Interestingly, analysis of cell shape at the interface between the two populations revealed that both wild-type and $s c r i b^{K D}$ cells become elongated at the site of contact (Fig. 2g,h), indicating that they are under anisotropic stress. Moreover, the cells in both populations move in the direction of their short axis (Fig. 2i), suggesting that they could be locally compressed. This could be the result of wild-type cells beginning migration and locally 'piling up' against the $s c r i b^{K D}$ cells. In agreement with this, particle image velocimetry (PIV) and single-cell tracking revealed that wild-type cells begin migrating towards $s c r i b^{K D}$ cells on average $\sim 2 \mathrm{~h}$ before the $s c r i b{ }^{K D}$ cells start migrating away (Fig. 2j,k and Supplementary Movie 6). Together, the chronology of these events and the local cellular deformations suggest that cells might engage in a behaviour similar to the 'chase and run' migration reported for other cell types ${ }^{29}$. These experiments do not distinguish whether $s c r i b{ }^{K D}$ cells are pushed by wild-type cells or, conversely, whether $s c r i b^{K D}$ cells self-compact to avoid closer interaction wild-type cells. However, it is clear that as migration progresses, scrib $K D$ cells become corralled by wild-type cells and are compacted and eliminated (Supplementary Movie 7), indicating that this behaviour may facilitate compaction and outcompetition of $s c r i b{ }^{K D}$ cells.

To directly test the relevance of directional cell migration in the elimination of $s c r i b^{K D}$ cells, we next sought to disrupt this behaviour. Adhesion molecules play an important role in collective cell migration ${ }^{30}$ and have also been implicated in 'chase and run' among mesenchymal cells ${ }^{29}$. In addition, scribble downregulation has previously been shown to induce intracellular accumulation of E-cadherin ${ }^{23,31}$ and we found that it causes an increase of both total and cell surface E-cadherin levels (Supplementary Fig. 2e-g). We therefore reasoned that targeting E-cadherin-mediated adhesion might disrupt directional migration between the wild-type and $s c r i b{ }^{K D}$ cells. We undertook two separate approaches and found that either blocking E-cadherin function in both populations, through a combination of low calcium and addition of a blocking antibody (Fig. 2l-o and Supplementary Movie 8), or silencing E-cadherin only in wild-type cells ( $E$-cad ${ }^{K D}$ (ref. 32 ); Fig. 2 p) was sufficient to inhibit directional migration. Interestingly, disruption of E-cadherin inhibited active cell compaction (Fig. 2l,m, Supplementary Movie 8 and quantification in Fig. 2n) and resulted in delayed elimination of $s c r i b^{K D}$ cells (Fig. 2l,m, Supplementary Movie 8 and quantification in Fig. 2o). However, it did not rescue the $s c r i b^{K D}$ cells from cell competition, since they were eventually eliminated as the culture became progressively more crowded due to proliferation (Fig. 2l,m and Supplementary Movie 8).

Having established that E-cadherin-mediated adhesion is involved in contact-induced migration between wild-type and $s c r i b^{K D}$ cells, we next asked whether the upregulation of E-cadherin observed in $s c r i b^{K D}$ cells (Supplementary Fig. 2e-g) plays a role in this directional cell movement. We therefore generated an inducible double $s c r i b^{K D}$ E-cadherin knockdown cell line $\left(s c r i b^{K D} E-c a d^{K D}\right)$ and specifically selected clones that displayed partial silencing, enough to bring E-cadherin down to wild-type levels (Fig. 2q, right panel and Supplementary Fig. 2h,i). Indeed, partial downregulation of E-cadherin inhibited contactinduced migration, suggesting that high E-cadherin levels in the $s c r i b^{K D}$ cells are required for this process (Fig. $2 \mathrm{q}$ and Supplementary Movie 9). As expected, these clones were still outcompeted by wild-type cells (Supplementary Fig. 2j). In contrast, we found that E-cadherin upregulation alone is not sufficient to cause contact-induced migration, as cells overexpressing E-cadherin at levels comparable to those of $s c r i b^{K D}$ cells (Supplementary Fig. 2k) did not engage in directional cell migration with wild-type cells upon contact (Supplementary Fig. 2l). Altogether, we conclude that directional cell migration, by enabling corralling and active compaction of $s c r i b^{K D}$ cells, promotes but is not required for mechanical cell competition, and that E-cadherin is necessary for corralling and active compaction but it does not impact on loser cell status.

p53 is activated in $s c r i b^{K D}$ cells before cell competition. Key to the outcompetition of $s c r i b{ }^{K D}$ cells is their hypersensitivity to compaction (Fig. 1k-q). To identify genes and pathways involved in this behaviour, we carried out transcriptional profiling of scrib ${ }^{K D}$ cells (scrib ${ }^{K D}+$ TET) and compared it with the transcriptomes of control MDCK cells $\left(s c r i b{ }^{K D}-\right.$ TET) and, importantly, of an isolate of $s c r i b^{K D}$ cells that is resistant to cell competition $\left(s c r i b^{R E S}\right)$. Despite maintaining scribble gene knockdown (Supplementary Fig. 3a), the $s c r i b^{R E S}$ cells do not display elevated E-cadherin (Supplementary Fig. 3b), do not engage in contact-induced migration with wild-type cells (Supplementary Fig. 3c) and are not outcompeted in cell competition assays (Supplementary Fig. 3d and Supplementary Movie 10). Notwithstanding these fundamental differences, we observed that the $s c r i b^{K D}$ transcriptome is still substantially closer to $s c r i b^{R E S}$ (with 523 differentially expressed genes) than to control (scrib ${ }^{K D}$ - TET) cells (with 1,645 differentially expressed genes; Fig. 3a, left and Supplementary Data 1 and 2). This allowed us to rule out all genes that are differentially expressed in $s c r i b{ }^{K D}$ versus wild-type cells but are similarly expressed between $s c r i b^{K D}$ and $s c r i b^{R E S}$, as these are clearly not sufficient to induce cell competition. Instead, we focused on the small intersection of 306 genes that are differentially expressed between wild-type and $s c r i b{ }^{K D}$ cells but are also different between $s c r i b^{K D}$ and $s c r i b^{R E S}$ cells (Fig. 3a and Supplementary Data 3).

Gene Ontology term enrichment analysis highlighted p53 signalling as the top functionally enriched pathway (Fig. 3a, middle). A number of known p53 target genes were moderately upregulated in $s c r i b{ }^{K D}$ cells, suggesting p53 activation (Fig. 3a, right). Consistent with this, we found that p21 (a known p53 target $^{33}$ and the most highly upregulated p53 target in our gene list; Fig. 3a) is specifically upregulated upon scribble knockdown in $s c r i b^{K D}$ cells (Fig. 3b, Supplementary Fig. $3 \mathrm{e}$ and Supplementary Fig. 4 d,e) but not in $s c r i b^{R E S}$ cells (Fig. 3b) and that p53 levels are higher in $s c r i b^{K D}$ cells than in wild-type cells (Fig. 3c,d and Supplementary Fig. 3f), confirming pathway activation. Thus, scrib ${ }^{K D}$ cells have high baseline p53 activity and this correlates with their loser status.

p53 is further elevated in $s c r i b^{K D}$ cells by compaction. Next we asked whether cell competition affects p53 activity. Interestingly, we found that in competing conditions, p53 levels in scrib ${ }^{K D}$ cells increase above their already elevated baseline level, in a way that correlates with the degree of cell compaction (Fig. $3 c-e ; r=0.56$ by non-parametric Spearman correlation). This suggested that compaction increases p53 levels or, conversely, that higher p53 levels enable compaction. To distinguish between these two possibilities, we looked at how compression alone affects p53, using deformable PDMS substrates as before (Fig. 1o-q). Importantly, we found that compression alone causes an increase in p53 levels (Fig. 3f,g), as seen during competition. This indicates that cell competition induces further p53 activation in the $s c r i b^{K D}$ cells via compaction-induced mechanical stress.

Given that p53 is upregulated during cell competition, we next sought to ask whether it contributes to this process. Therefore we mutated p53 in $s c r i b{ }^{K D}$ cells by CRISPR-mediated mutagenesis $\left(\right.$ scrib $^{K D} \mathrm{p}^{-1-}$ cells, Supplementary Fig. 4a,b). The scrib $3^{K D}$ 
$p 53^{-1-}$ cells failed to upregulate p21 following ultraviolet irradiation (Supplementary Fig. 4b) or scribble knockdown (Supplementary Fig. 4c-e), confirming functional p53 inactivation. Strikingly, we found that $\mathrm{p} 53$ inactivation in $s c r i b^{K D}$ $p 53^{-1-}$ cells was sufficient to partially rescue their low homeostatic cell density (Fig. 3h) and their hypersensitivity to compaction (Fig. 3i). Remarkably, genetic (using $s c r i b{ }^{K D} p 53^{-1-}$ cells) or chemical (using the inhibitor Pifithrin- $\alpha$ ) inhibition of

a

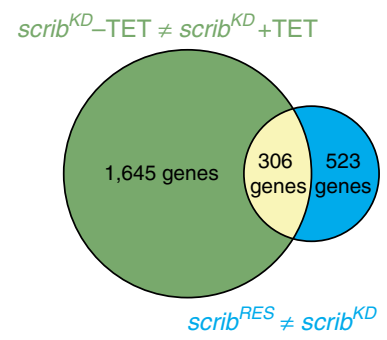

\begin{tabular}{l}
\multicolumn{1}{c|}{ GO terms } \\
- p53 signaling \\
- Pathways in cancer \\
- Adherens junctions \\
- MAPK signaling \\
- VEGF signaling \\
- Cell cycle
\end{tabular}

\begin{tabular}{|lcc|}
\hline p53 targets & Fold change & $\boldsymbol{P}$ value \\
Cdkn1a (p21) & 3.55 & $2.7 \mathrm{E}-107$ \\
Cyclin G1 & 2.76 & $3.14 \mathrm{E}-70$ \\
MDM2, E ubiquitin protein ligase & 2.07 & $7.19 \mathrm{E}-40$ \\
Serpin peptidase inhibitor, clade B, member 5 & 1.91 & $8.26 \mathrm{E}-23$ \\
Serpin peptidase inhibitor, clade E, member 1 & 1.88 & $1.74 \mathrm{E}-25$ \\
\hline
\end{tabular}

b

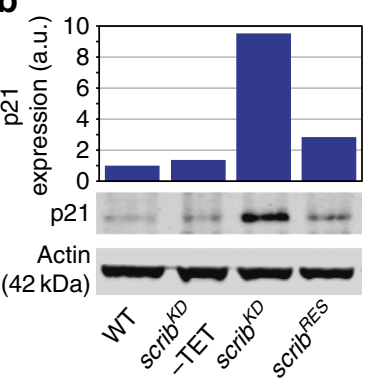

$\mathbf{f}$

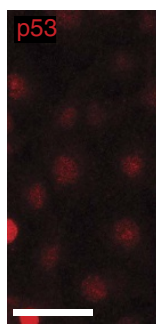

Control scrib $^{K D}$

g

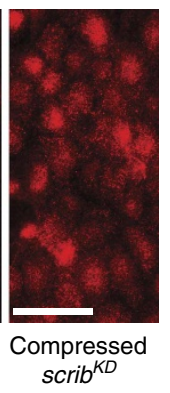

j c

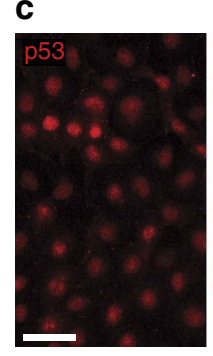

$s c r i b^{K D}$ d

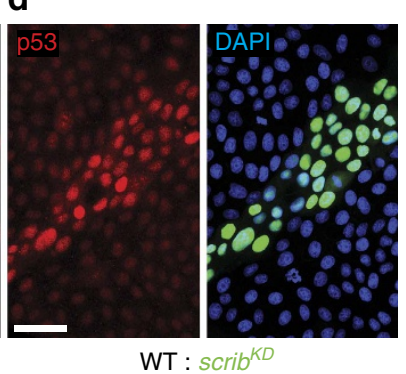

h

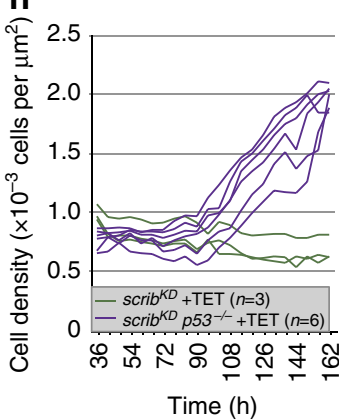

Time ( $h$ )

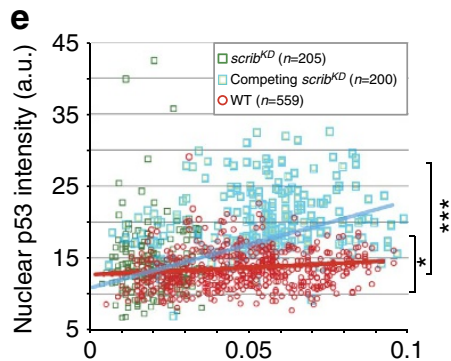

Gaussian weighted cell density
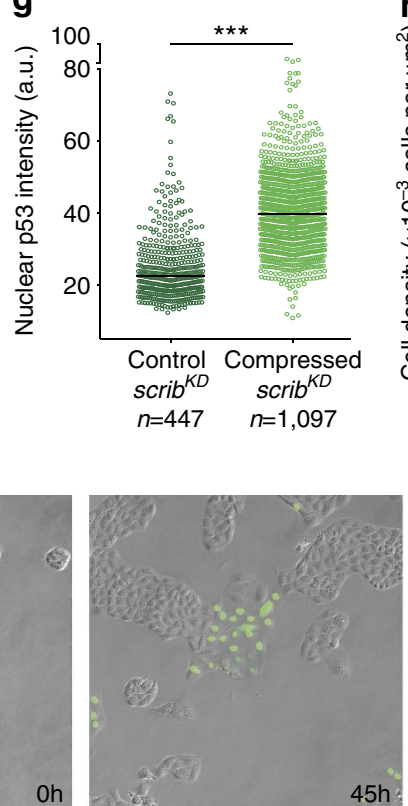

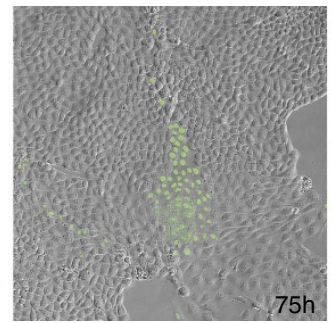

i
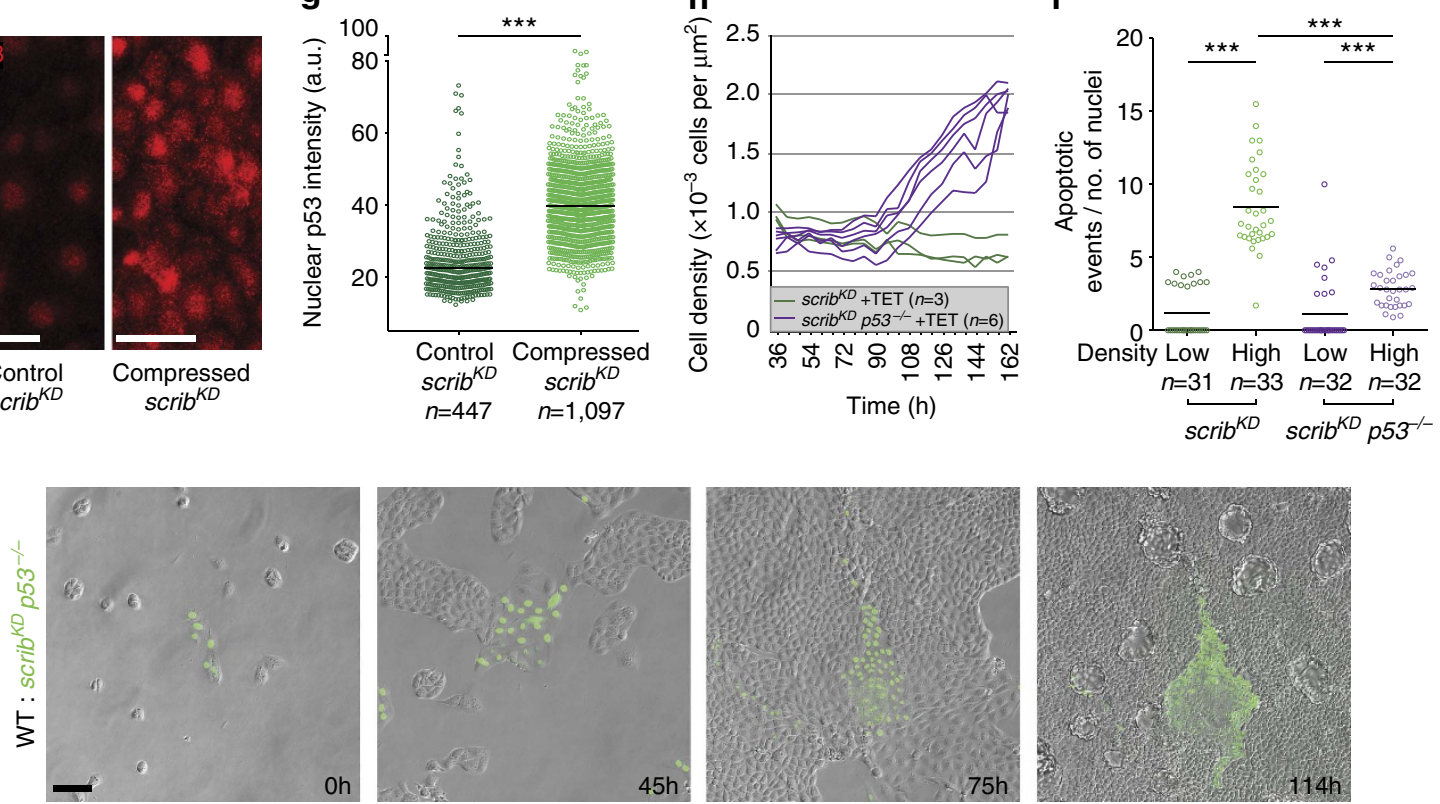

Figure 3 | p53 is activated in scrib ${ }^{K D}$ cells before competition and further p53 elevation upon compaction causes competition-induced cell death. (a) Left, transcriptional profiling of scrib ${ }^{K D}$ cells without tetracycline (TET) versus scrib ${ }^{K D}$ cells with TET (green) and of scrib ${ }^{K D}$ cells with TET versus scrib ${ }^{K D}$ cells resistant to competition (scrib ${ }^{R E S}$ ) with TET (blue), and corresponding intersection of differentially expressed genes (yellow). Middle, list of pathways functionally enriched in the yellow intersection. Right, list of p53 targets found in this intersection and corresponding fold change difference between scrib ${ }^{K D}$ cells $-/+$ TET. Three biological replicates for scrib ${ }^{K D}$ cells $-/+$ TET and two biological replicates for scrib ${ }^{R E S}$ cells + TET. (b) Western blot against p21 with LICOR quantifications and normalization to Actin. (c,d) p53 staining of pure scrib ${ }^{K D}$ cells (c) and of co-cultures of GFP-labelled scrib ${ }^{K D}$ and wild-type (WT) cells (d). (e) Graph showing single-cell nuclear p53 intensity plotted against cell density from images as in $\mathbf{c}$ and $\mathbf{d} ;{ }^{\star} P<0.05$ by KS test comparing p53 levels in pure scrib ${ }^{K D}$ versus $W T ;{ }^{\star \star \star} P<0.0005$ by KS test comparing competing scrib ${ }^{K D}$ versus WT. Non-parametric Spearman correlation; red line $=$ WT cells; blue line $=$ competing scrib ${ }^{K D}$ cells. $(\mathbf{f}, \mathbf{g})$ p53 staining in pure scrib ${ }^{K D}$ cells on PDMS substrate $+/-$ compression (f) and quantification showing single-cell nuclear p53 intensity (g) from images as in $\mathbf{f}$; black bars = median. (h) Time-resolved density measurement of growing scrib ${ }^{K D}$ cells and scrib ${ }^{K D} p 53^{-/-}$cells. (i) Quantification of cell death (cleaved Caspase-3) for scrib ${ }^{K D}$ cells versus scrib ${ }^{K D} p 53^{-/-}$cells on PDMS substrate $+/-$ compression; black bars = mean; data from three biological replicates across two independent experiments. (j) Stills from time-lapse movies of WT and GFP-labelled scrib ${ }^{K D} \mathrm{p5}^{-/-}$co-cultures, see corresponding Supplementary Movie $11 ; n=$ cell number in $\mathbf{e}$ and $\mathbf{g}$ or $n=$ number of imaged fields of cells in h and $\mathbf{i}$. a.u. $=$ arbitrary units, here and throughout all the figures. ${ }^{\star} P<0.05,{ }^{\star \star \star} P<0.0005$ by KS test. 
p53 in scrib ${ }^{K D}$ cells was also sufficient to prevent their outcompetition (Fig. $3 \mathrm{j}$ and Supplementary Movie 11; Supplementary Fig. 4f). Furthermore, scrib ${ }^{K D} p 53^{-/-}$cells maintained high E-cadherin levels (Supplementary Fig. 4g) and still displayed contact-induced migration (Supplementary Fig. 4h), demonstrating again that corralling is not sufficient for competition. Altogether, we conclude that high baseline p53 activity in $s c r i b^{K D}$ cells is associated with their loser status and is required for them to acquire a low homeostatic cell density and hypersensitivity to compaction, two key features of the mechanical loser status.

Interestingly, though it has long been established that scribble ${ }^{-1-}$ cells are eliminated by cell competition in Drosophila ${ }^{34,35}$, when we tested whether this might happen via mechanical insults in wing imaginal discs we found that, unlike in MDCK cells, scribble ${ }^{-9}$ - wing disc cells did not upregulate E-cadherin (Supplementary Fig. 5a,b) and their outcompetition was not rescued by p53 inhibition (Supplementary Fig. 5c). It is possible that scribble ${ }^{-I-}$ cells are not eliminated by mechanical cell competition in Drosophila or that the function of Scribble or p53 may not be conserved in this process. Alternatively and perhaps more likely, mechanical cell competition may be redundant with other mechanisms of cell competition that have been described to target scribble ${ }^{-1-}$ cells in that system $^{36,37}$.

ROCK activates p38 leading to p53 elevation and cell death. We next wondered how mechanical stress might lead to p53 activation. A potential candidate was p38 signalling, as it is required for $s c r i b{ }^{K D}$ cell competition ${ }^{23}$, is known to promote $\mathrm{p} 53$ activity $^{38-40}$ and has also been involved in the response to mechanical stress ${ }^{41}$. Consistent with an involvement of $\mathrm{p} 38$, we found that compression alone causes an increase in active phosphorylated (T180/Y182) p38 (ref. 38; P-p38) in scrib $^{K D}$ cells (Fig. 4a,b) and that chemical inhibition of this pathway partially rescues both the homeostatic density of $s c r i b^{K D}$ cells (Fig. 4c) and their compaction hypersensitivity (Fig. 4d). Moreover, the upregulation of $\mathrm{p} 53$ in competing scrib ${ }^{\mathrm{K}} D_{\text {cells }}$ was reduced by p38 inhibition (Fig. 4e). We conclude that in $s c r i b^{K D}$ cells, compression induces $\mathrm{p} 53$ via activation of $\mathrm{p} 38$.

We next asked how compression of $s c r i b^{K D}$ cells causes p38 activation. We monitored cytoskeletal changes induced by compression and found that both cortical Actin (by phalloidin staining) and active phosphorylated-myosin (P-Myosin) are upregulated in compacted $s c r i b^{K D}$ cells during competition (Fig. 4f,g). Since the cytoskeletal regulator $\mathrm{ROCK}^{42}$ is one of the main kinases responsible for Myosin phosphorylation, this suggested that ROCK might be activated. Indeed P-Myosin upregulation was reduced in the presence of a ROCK inhibitor (Supplementary Fig. 6a,b) and the ROCK target phospho-MYPT1 (ref. 43; p-MYPT1) was also elevated in compacted $s c r i b{ }^{K D}$ cells (Fig. 4h), indicating that ROCK is activated in compacted $s c r i b^{K D}$ cells. This was potentially relevant because ROCK has been shown to phosphorylate p38 (ref. 44). Thus, to ask whether ROCK is upstream of p38 activation, we compressed pure cultures of $s c r i b^{K D}$ cells in the presence or absence of a ROCK inhibitor and looked at P-p38 levels. ROCK inhibition led to a partial reduction of P-p38 levels, thus placing ROCK upstream of p38 signalling (Fig. 4i,j). In addition, ROCK inhibition was sufficient to partially rescue the homeostatic density of $s c r i b K D$ cells (Fig. 4k) and compression-induced cell death (Fig. 4l). Importantly, inhibition of ROCK was also sufficient to prevent the out-competition of $s c r i b{ }^{K D}$ cells, with no appreciable cell death observed even though cells were compacted far beyond standard competition densities (Fig. $4 \mathrm{~m}$ and Supplementary Movie 12). Altogether, these experiments indicate that mechanical cell competition is caused by compaction-induced
ROCK activation, which activates p38, leading to p53 elevation and cell death. Interestingly, ROCK has also been implicated in apical extrusion of dying or crowded MDCK cells ${ }^{45,46}$. However, in the case of Scribble competition, ROCK has a different function, as it is involved in p53 activation and cell death. In addition, while in that context ROCK was activated by S1P2 and Piezo signalling ${ }^{45,46}$, inhibition of these pathways had no effect on Scribble cell competition (Supplementary Fig. 7a,b), suggesting a distinct upstream activation mechanism.

p53 activation turns wild-type cells into mechanical losers. Finally, we decided to address how scribble knockdown earmarks cells as losers. Our data indicated that a loser cell status is not an obligate outcome of scribble silencing, as we could isolate $s c r i b^{K D}$ cells that are competition resistant (scrib ${ }^{R E S}$ cells; Supplementary Fig. 3d). Instead, our data showed that p53 is necessary for competition and that mild $\mathrm{p} 53$ elevation is required for $s c r i b^{K D}$ cells to acquire key features of the mechanical loser status (Fig. 3h,i). This prompted us to investigate whether $\mathrm{p} 53$ might actually be sufficient to induce the mechanical loser status and cell competition. Nutlin-3, a chemical inhibitor of the E3 ubiquitin ligase MDM2 (Mouse Double Minute 2 (ref. 47)), activates p53 in a dosedependent manner. This allowed us to establish conditions to induce mild p53 activation in wild-type MDCK cells. Strikingly, low-level p53 activation was sufficient to induce cell flattening (Fig. 5a) and to lower the homeostatic density of wild-type cells (Fig. 5b). Remarkably, Nutlin-3 treatment was also sufficient to induce compaction hypersensitivity (Fig. 5c). Thus, mild p53 activation is sufficient to induce in wild-type cells all the features that we observed in $s c r i b^{K D}$ cells that are hallmarks of their mechanical loser status. Therefore, we next asked whether differential p53 levels are sufficient to induce mechanical cell competition. To test this, we generated a p53 knockout cell line $\left(p 53^{-/-}\right)$, which we then co-cultured with wild-type cells. Not surprisingly, simply mixing wild-type and $p 53^{-/-}$cells was not sufficient to induce competition (Supplementary Fig. 8a). Strikingly however, mild p53 activation in wild-type cells, by Nutlin-3 addition at sublethal doses, caused the elimination of these cells specifically in the co-culture, but not when they were cultured alone (Fig. $5 \mathrm{~d}$, Supplementary Fig. 8b and Supplementary Movie 13). Importantly, p53-induced cell competition was indistinguishable from scribble cell competition, as it resulted in loser cell compaction (Fig. 5e) and only caused elimination when cells were compacted by $p 53^{-1-}$ cells (Fig. 5d). Overall, these results demonstrate that mild elevation of p53 is sufficient to phenocopy Scribble cell competition and induce both hypersensitivity to cell crowding and the mechanical loser status in otherwise wild-type cells.

To demonstrate the existence of p53-mediated mechanical cell competition beyond the MDCK experimental paradigm, we turned to primary cultures of epithelial cells, specifically to mouse tracheal epithelial cells (MTECs), and looked for evidence of this process. Under normal conditions, confluent MTEC monolayers show little proliferation or change in cell density (Fig. 5f,g, compare first and second time points, and Supplementary Movie 14 , left, before Nutlin-3 addition). Interestingly however, when we induced mild elevation of p53 (by Nutlin-3 treatment) in these cultures, we found that this results in a $26 \%$ average reduction in cell density, accompanied by cell extrusion, suggesting acquired hypersensitivity to crowding (Fig. 5f,g, compare before and after Nutlin-3 addition, and Supplementary Movie 14, left, after Nutlin-3 addition). To test whether differential levels of p53 could induce cell competition in MTECs, we mixed Tomatolabelled wild-type MTECs (MTEC Tomato; from Rosa26RnTomato-nGFP mice ${ }^{48}$ ) either with unlabelled wild-type MTECs or with unlabelled p53 null MTECs (MTEC $p 53^{-1-}$; 
a

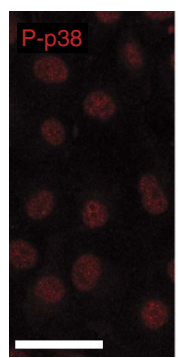

Control scrib $^{K D}$ b

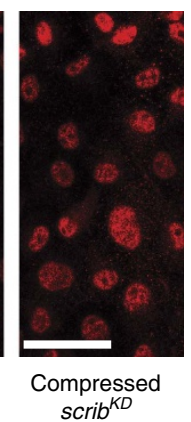

e

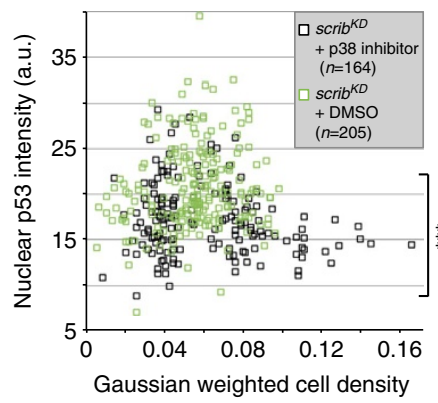

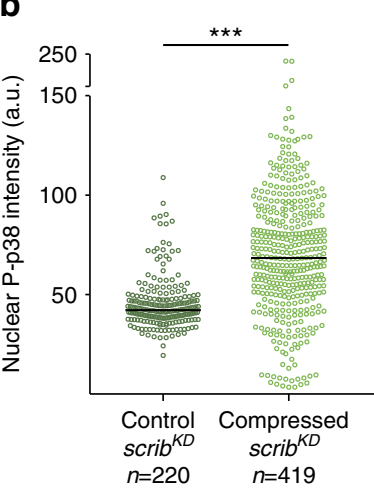

f

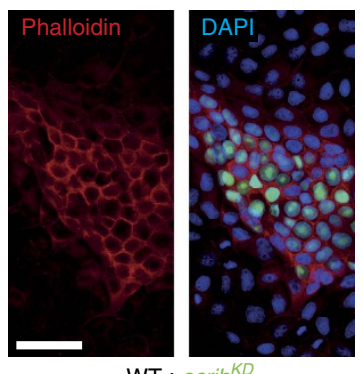

c

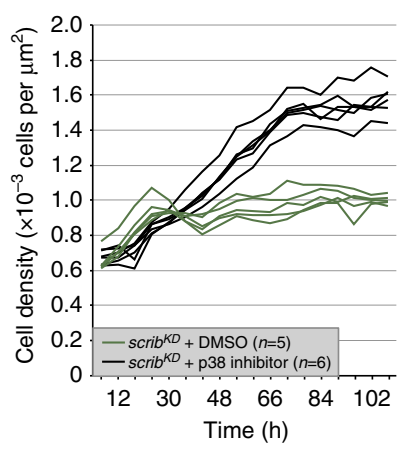

g

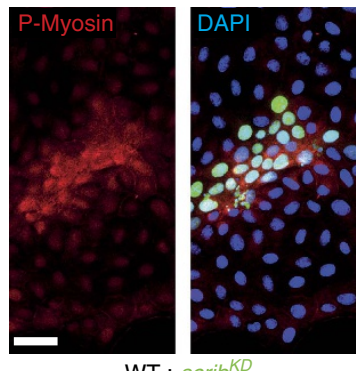

WT : scrib ${ }^{K D}$

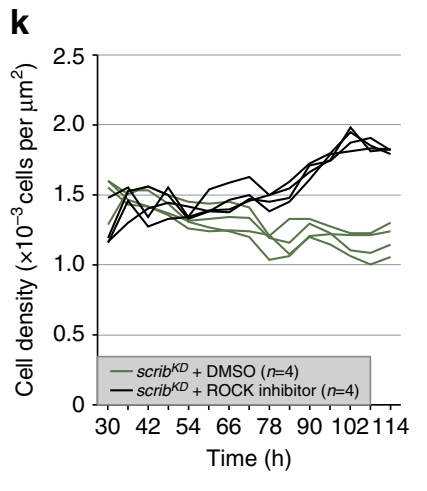

d

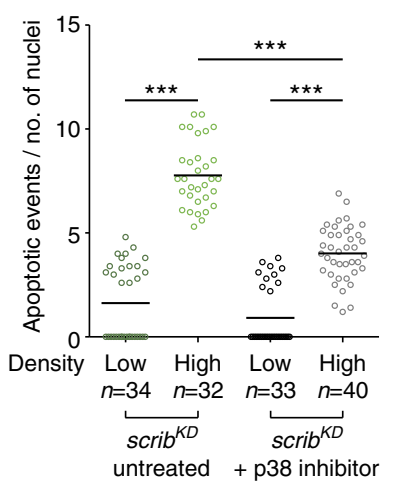

h

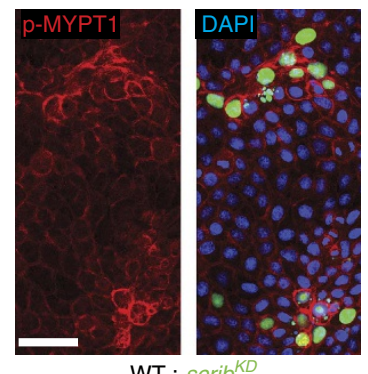

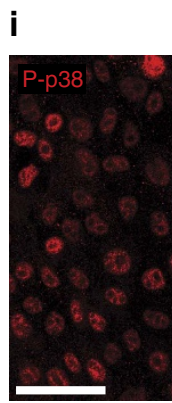

scrib $^{K D}$ untreated j

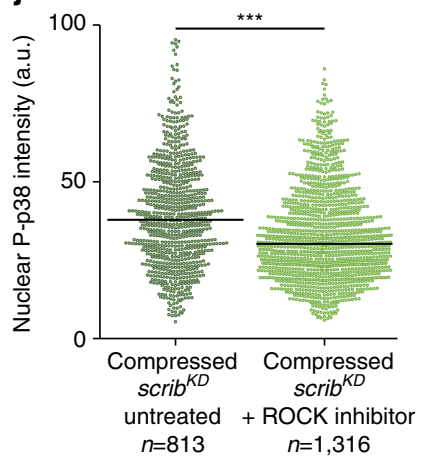

m
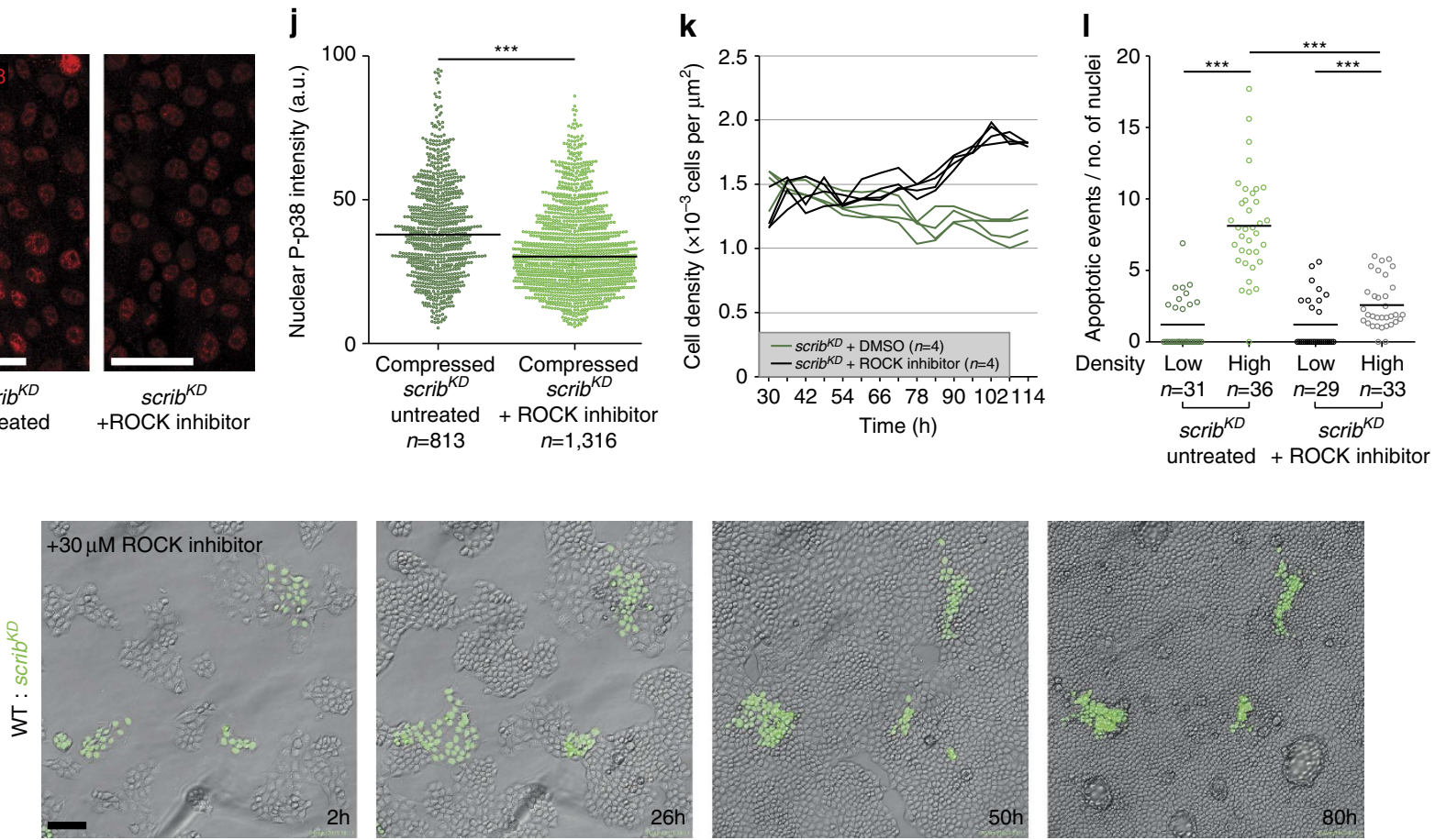

Figure 4 | During mechanical cell competition ROCK activates p38 leading to p53 elevation. (a) Phosphorylated p38 (P-p38) staining in pure scrib ${ }^{K D}$ cells $+/$ - compression. (b) Single-cell nuclear P-p38 intensity from images as in $\mathbf{a}$; black bars = median. (c) Time-resolved density measurement of growing scrib ${ }^{K D}$ cells $+/-$ p38 inhibitor. (d) Quantification of cell death (cleaved Caspase-3) of scrib ${ }^{K D}$ cells with or without compression and $+/-$ p38 inhibitor; black bars = mean; pooled data from three biological replicates across two independent experiments. (e) Single-cell nuclear p53 signal intensity in competing scrib ${ }^{K D}$ cells $+/-$ p38 inhibitor, plotted against cell density. (f-h) F-Actin (phalloidin-stained, f), phosphorylated Myosin-II (P-Myosin, $\mathbf{g}$ ) and phosphorylated MYPT1 ( $\mathrm{p}-\mathrm{MYPT1}, \mathbf{h}$ ) are elevated in compacted GFP-labelled scrib ${ }^{K D}$ cells compared with wild-type (WT) cells during competition.

(i) P-p38 staining in compressed scrib ${ }^{K D}$ cells $+/-$ ROCK inhibitor. (j) Single-cell nuclear P-p38 intensity from images as in $\mathbf{i}$; black bars $=$ median.

(k) Time-resolved density measurement of growing scrib ${ }^{K D}$ cells $+/-$ ROCK inhibitor; two independent repeats. (I) Quantification of cell death (cleaved Caspase-3) in scrib ${ }^{K D}$ cells with or without compression and $+/-$ ROCK inhibitor; black bars = mean; pooled data from three biological replicates across two independent experiments. (m) Stills from time-lapse movies of WT and GFP-labelled scrib ${ }^{K D}$ co-cultures treated with ROCK inhibitor ( $30 \mu M$ ), see corresponding Supplementary Movie 12; $n=$ cell number in $\mathbf{b}, \mathbf{e}$ and $\mathbf{j}$ or $n=$ number of imaged fields of cells in $\mathbf{c}, \mathbf{d}, \mathbf{k}$ and $\mathbf{I}$. ${ }^{\star \star \star} P<0.0005$ by $K S$ test. 
a

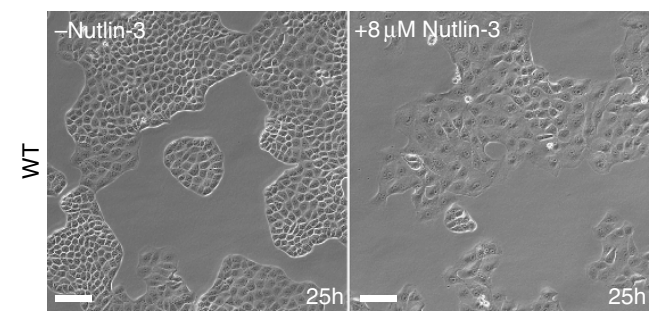

d

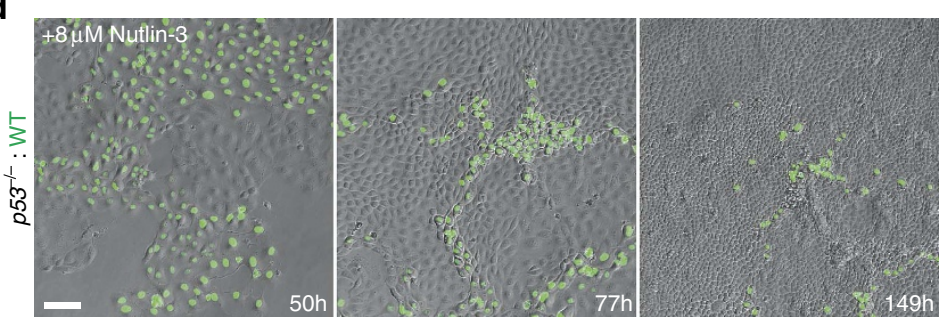

f

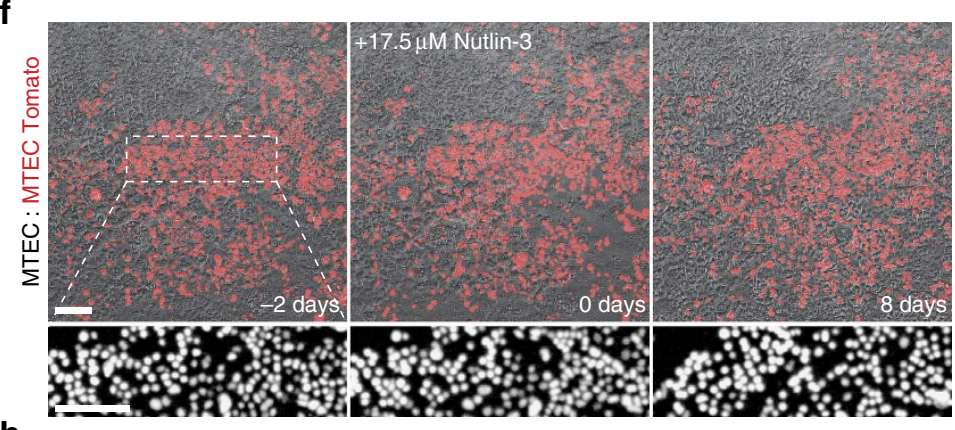

h

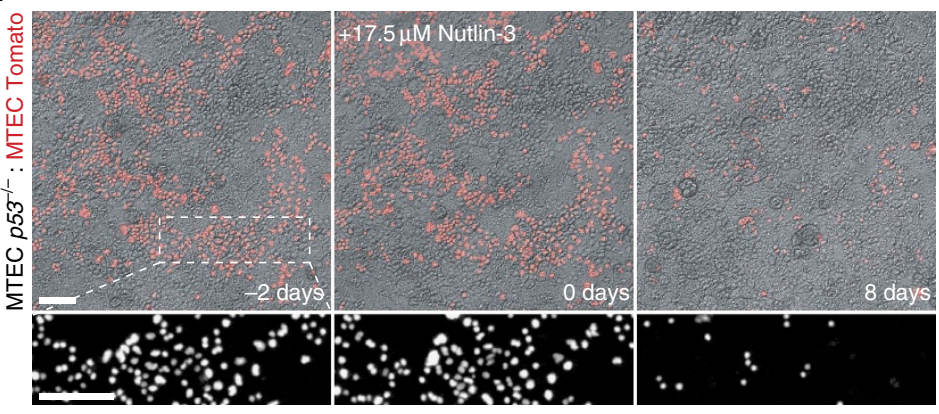

j

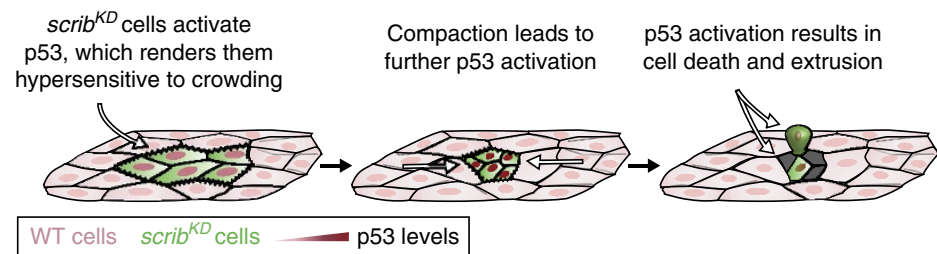

C

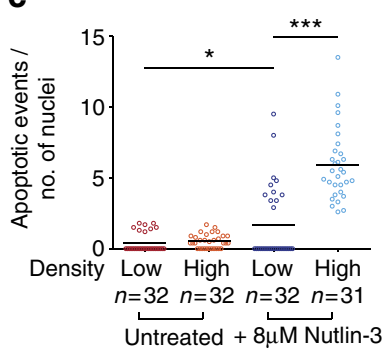

e

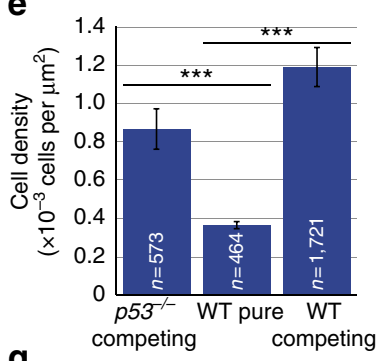

g

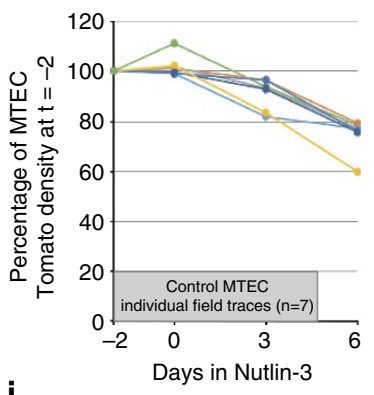

i

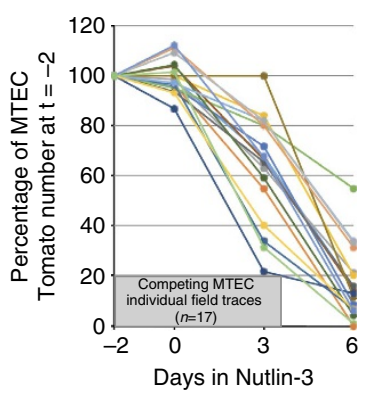

k

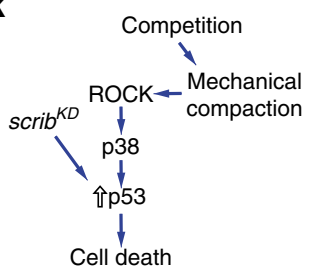

Figure 5 I p53 activation is sufficient to induce crowding hypersensitivity and mechanical cell competition. (a) Addition of Nutlin-3 ( $8 \mu M$ ) causes flattening of wild-type (WT) MDCK cells; $n=4$ fields per repeat. (b) Time-resolved cell density measurement of growing WT MDCK cells $+/-$ Nutlin-3 $(8 \mu \mathrm{M})$. (c) Quantification of cell death (cleaved Caspase-3) of WT MDCK cells with and without compression and $+/-$ Nutlin-3 (8 $\mu$ M); black bars = mean; three biological replicates from two independent experiments. (d) Stills from time-lapse movies of WTand p53-/ - MDCK co-cultures with Nutlin-3 $(8 \mu \mathrm{M})$ see corresponding Supplementary Movie 13. (e) Cell density measurement from movies as in d; mean \pm s.e.m. (f) Stills from time-lapse movies of primary cultures of unlabelled and Tomato-labelled WT MTECs (see corresponding Supplementary Movie 14). Nutlin-3 (17.5 $\mu$ M) was added at $t=0$. (g) Time-resolved cell density measurement from movies as in $\mathbf{f}$ of WT MTECs before and after Nutlin-3 (17.5 $\mu$ M) addition. (h) Stills from timelapse movies of primary cultures of unlabelled $p 53^{-/-}$and Tomato-labelled WT MTECs (see corresponding Supplementary Movie 15). Nutlin-3 (17.5 $\mu$ M) was added at $t=0$. (i) Time-resolved measurement of cell number from movies as in $\mathbf{h}$ of WT MTECs before and after Nutlin-3 (17.5 $\mu \mathrm{M})$ addition. (j,k) Model of mechanical cell competition of scrib ${ }^{K D}$ cells; $n=$ cell number in $\mathbf{e}$ or $n=$ number of imaged fields of cells in $\mathbf{b}, \mathbf{c}, \mathbf{g}$ and $\mathbf{i}$. For $\mathbf{c}$ and $\mathbf{e}$, data are pooled from three biological replicates. ${ }^{\star} P<0.05,{ }^{\star \star \star} P<0.0005$ by $\mathrm{KS}$ test. 
from p53 null mice). Before Nutlin-3 addition, the proportion of wild-type (Tomato) MTECs in the monolayer did not change for several days when co-cultured with either $p 53^{-1-}$ cells or more wild-type cells (Fig. $5 \mathrm{f}-\mathrm{i}$, first two time points, and Supplementary Movie 14, before Nutlin-3 addition). However and strikingly, Nutlin-3 addition induced robust cell competition specifically in wild-type/p53-1- MTEC co-cultures, causing the number of wild-type cells to plummet within 6 days to $\sim 17 \%$ of their starting number, with pronounced cell death and fragmentation (Fig. 5h,i and Supplementary Movie 14, right). Thus, mild p53 elevation is sufficient to induce crowding hypersensitivity and mechanical cell competition in MTEC cultures.

\section{Discussion}

In summary, our work demonstrates that in addition to molecular signals, cells use mechanical means to compete (see model in Fig. 5 j,k), a concept that had previously only been speculated about and proposed on theoretical grounds ${ }^{19,49}$. We show that hypersensitivity to crowding provides an additional route to the loser cell status, leading to mechanical cell competition and the elimination of loser cells. One interesting prediction of our findings is that they suggest that competition could take place between genetically identical cells if they are endowed with differential sensitivity to mechanical stress or if they reside in tissues with varying mechanical properties ${ }^{50,51}$, a hypothesis that should be investigated. In addition, given the involvement of p53, a general sensor of cell stress, we suggest that mechanical cell competition may be widespread among the damaged cells. Moreover, future work should also examine the implications of our findings on the behaviour of cancer cells. Since $p 53$ is one of the most commonly mutated genes in cancer ${ }^{52}$, our findings suggest that its loss could enable neoplastic cells (scribble is a tumour-suppressor gene $e^{53,54}$ ) to evade mechanical cell competition. Identifying the physiological contexts where mechanical cell competition plays a role may help better understand tissue biology and potentially cancer formation.

Note added in proof: Evidence of mechanical competition in Drosophila was reported just prior to acceptance of this work ${ }^{55}$.

\section{Methods}

\section{Antibodies and materials. For immunofluorescence we used}

Rabbit anti-p53 antibody (1:750, Cell Signaling Technology \#9382), rabbit antip21 antibody (1:200, Santa Cruz sc-397). In functional tests, both antibodies show an increase in staining intensity + ultraviolet- $C$ treatment and a reduction or complete absence of staining in $s c r i b^{K D} p 53^{-/-}$and $p 53^{-/-}$cells (Supplementary Fig. 4b). In addition, the anti-p21 antibody is documented to cross-react in canine. Mouse anti-E-cadherin antibody (1:600 total stain or 1:200 surface stain ${ }^{56}$ ), rabbit anti-E-cadherin antibody (1:500 total stain or 1:50 surface stain $\left.{ }^{57}\right)$, both documented to cross-react in canine. Rabbit anti-P-p38 MAPK (T180/Y182) antibody (1:50, Cell Signaling Technology \#9215) was used as in Norman et al. ${ }^{23}$ Rabbit anti-P-Myosin light chain (phospho S20) antibody (1:100, Abcam ab2480), predicted to cross-react with all mammals. Goat p-MYPT1 (Thr 853) (1:50, Santa Cruz sc-17432) antibody, documented to cross-react in canine. Rabbit anti-cleaved Caspase-3 antibody (1:200, Cell Signaling Technology \#9661s), predicted to crossreact in canine based on $100 \%$ sequence homology. DAPI $\left(1 \mu \mathrm{g} \mathrm{ml}^{-1}\right.$ Invitrogen); Alexa Fluor conjugated secondary antibodies (1:1,000, Invitrogen); Alexa Fluor-568 and Alexa Fluor-647 conjugated phalloidin (1:40, Invitrogen).

For western blotting we used:

Rabbit anti-p53 antibody (1:1000, Cell Signaling Technology \#9382), rabbit anti-p21 antibody (1:500, Santa Cruz sc-397). Goat anti-Scribble antibody (1:500, Santa Cruz sc-11048), functional tests show a decrease in signal intensity in $s c r i b{ }^{K D}$ cells + TET and it is documented to cross-react in canine (Supplementary Fig. 3a). Mouse anti-E-cadherin antibody (1:1,000; (ref. 56)), rabbit anti- $\beta$-tubulin antibody (1:50,000, Abcam ab6046), HRP conjugated secondary antibodies (1:3,000, BioRad) and IRDye infrared fluorescent dyes (1:10,000, LI-COR).

Inhibitors and treatments were used at the following concentrations: Pifithrin- $\alpha$ (Sigma) $10 \mu \mathrm{M}$, p38 inhibitor SB202190 (Calbiochem) $10 \mu \mathrm{M}$, ROCK inhibitor Y27632 (Sigma) $30 \mu \mathrm{M}$, Piezo inhibitor gadolinium III chloride (Sigma) $100 \mu \mathrm{M}$, S1P2 inhibitor JTE013 (Tocris Bioscience) $10 \mu \mathrm{M}$, tetracycline (Sigma) $5 \mu \mathrm{g} \mathrm{ml}^{-1}$ (except for pre-treating scrib ${ }^{K D}$ cells for RNA-seq analysis where it was used at $10 \mu \mathrm{g} \mathrm{ml}^{-1}$ ), doxycycline (Sigma) $1 \mu \mathrm{g} \mathrm{ml}^{-1}$, Nutlin-3 (Cayman Chemicals) was added as specified.
Cell culture and plasmids. The cell lines used in this publication are not listed in the database of misidentified cell lines maintained by ICLAC. MDCK cell lines were authenticated in our laboratory by RNA sequencing, which confirmed their canine origin. All cell lines used in this publication have been tested in our laboratory and were found to be negative for mycoplasma infection (EZ PCR Mycoplasma Test Kit, Geneflow).

Wild-type MDCK, MDCK-pTR E-cadherin shRNA $\left(E c a d^{K D}\right)^{32}$ and MDCKpTR scribble shRNA $\left(s c r i b^{K D}\right)$ cells $^{23}$ were a kind gift from Yasuyuki Fujita. Wildtype and $E$-cad ${ }^{K D}$ MCDK cells were cultured in DMEM (21885; Invitrogen) supplemented with $10 \%$ fetal bovine serum (FBS, Invitrogen) in a humidified incubator at $37^{\circ} \mathrm{C}$ with $5 \% \mathrm{CO}_{2}$. The $s c r i b^{K D}$ cells were cultured as described for wild-type cells with the addition of blasticidin $50 \mu \mathrm{g} \mathrm{ml}^{-1}$ (Sigma) and G418 $800 \mu \mathrm{g} \mathrm{ml}^{-1}$ (Invitrogen) to the culture media. To establish MDCK cell lines that stably express a nuclear green fluorescent protein (GFP) or red fluorescent protein (RFP) marker, we used a modified pGIPZ-turboGFP-Puro (Thermo Scientific) plasmid where we replaced turbo-GFP with either GFP-NLS or RFP-NLS. Selection following infection was carried out with puromycin $\left(0.65 \mu \mathrm{g} \mathrm{ml}^{-1}\right.$, Sigma).

Resistant $s c r i b^{K D}$ MDCK cells $\left(s c r i b^{R E S}\right)$ were generated by culturing MDCKpTR scribble shRNA cells in $5 \mu \mathrm{g} \mathrm{ml}^{-1}$ tetracycline for 20 days. The resulting final population was expanded in the absence of tetracycline and tested for efficient Scribble knockdown by western blotting.

The MDCK $p 53^{-l-}$ and $s c r i b^{K D} p 53^{-1-}$ cells were generated using Cas9 D10A CRISPR technology. sgRNAs against canine TP53 were manually designed following published guidelines ${ }^{58}$

(p53_CRISPR\#1_Fw: 5'-GCAGAAGTGGCTGGCATCCT-3', p53_CRISPR\#2_Fw: $5^{\prime}$-CCCTGGACCGGCCCCCTCC- $\left.3^{\prime}\right)$.

sgRNAs were individually cloned into the PX461 vector ${ }^{58}$ and the pair was co-transfected into recipient cells. Pools of both $p 53^{-/-}$and $s c r i b^{K D} p 53^{-/-}$cells were generated by functional selection with Nutlin-3 $(20-30 \mu \mathrm{M})$ for 5-7 days and either used immediately or expanded from single cells. p53 knockout was verified by functional tests.

To knock down E-cadherin expression in MDCK scribble shRNA cells (scrib ${ }^{K D}$ $E$-cad $\left.{ }^{K D}\right)$, the recipient cells were stably transfected with a modified version (pSUPERIOR.hygro + gfp E-cadherin shRNA) of a plasmid provided by Yasuyuki Fujita (pSUPERIOR.neo + gfp E-cadherin shRNA ${ }^{32}$ ). Selection was carried out with Hygromycin B $\left(75 \mu \mathrm{g} \mathrm{ml}^{-1}\right.$, Invitrogen). To overexpress E-cadherin in wildtype MDCK cells, the E-cadherin-GFP $\mathrm{CDNA}^{59}$ was introduced into a modified pTRIPZ-turboRFP-Puro plasmid (Thermo Scientific) in which turboRFP was replaced by RFP-NLS (pTRIPZ-RFP-NLS-Puro). The cells infected with the pTRIPZ ECAD-GFP-P2A-RFP-NLS construct express doxycycline-inducible E-cadherin-GFP and RFP-NLS as a single transcript. Selection following infection was carried out with puromycin $\left(0.65 \mu \mathrm{g} \mathrm{ml}^{-1}\right.$, Sigma).

Primary mouse tracheal epithelial cells (MTECs) were obtained from 5-month-old animals from 26R-Tomato (Gt(ROSA)26Sortm1(CAG-tdTomato* EGFP*)Ees $)$ and p53-null (Trp53 $3^{\text {tm 1tyj }}$ ) strains, both of C57BL/6 background, using a protocol adapted from published methods ${ }^{60}$. Tracheas were dissected from the larynx to the bronchial main branches and collected in ice-cold DMEM:F12 (11330-32; Invitrogen) supplemented with a solution of 100 units $\mathrm{ml}^{-1}$ penicillin and $100 \mu \mathrm{g} \mathrm{ml}^{-1}$ streptomycin (Invitrogen). The muscle, vascular tissue and glands were then removed and the trachea cut into three to four rings. Each fragment was washed in phosphate-buffered saline (PBS) and then incubated in Dispase (BD Biosciences) at 7.5 Caseinolytic Units in PBS (total volume $450 \mu \mathrm{l}$ per trachea) for $25 \mathrm{~min}$ at room temperature (RT). Tracheal fragments were then transferred into ice-cold DMEM:F12 and the sheets of epithelial tissue were peeled off. The epithelial sheets and medium were transferred to an ice-cold $1.5 \mathrm{ml}$ tube, and pelleted twice at $500 \mathrm{~g}$ for $3 \mathrm{~min}$ with a PBS wash in between. The pellets were resuspended in $0.05 \% \mathrm{TE}$ (Invitrogen) supplemented with $5 \mathrm{mM}$ EDTA for $30 \mathrm{~min}$ at $37^{\circ} \mathrm{C}$. Five hundred microlitres of DMEM:F12 supplemented with $5 \%$ FBS was added to stop the reaction. The cells were pelleted $(500 \mathrm{~g}$, $3 \mathrm{~min}$ ), resuspended in MTEC/Plus media and plated on collagen-coated $\left(50 \mu \mathrm{g} \mathrm{ml}^{-1}\right.$ rat tail collagen I (BD Biosciences) $/ 0.02 \mathrm{M}$ acetic acid) 24 -well tissue culture inserts (BD Falcon) in MTEC/Plus media at approximately $5 \times 10^{4}$ cells per insert. The MTEC cells were cultured in MTEC/Plus media consisting of: DMEM:F12 basal media supplemented with a solution of 100 units $\mathrm{ml}^{-1}$ penicillin and $100 \mu \mathrm{g} \mathrm{ml}^{-1}$ streptomycin, $10 \mu \mathrm{g} \mathrm{ml}^{-1}$ insulin (Invitrogen), $5.5 \mu \mathrm{g} \mathrm{ml}^{-1}$ transferrin (Invitrogen), $6.7 \mu \mathrm{g} \mathrm{ml}^{-1}$ selenium (Invitrogen), $0.1 \mu \mathrm{g} \mathrm{ml}^{-1}$ cholera toxin (Sigma), $25 \mathrm{ng} \mathrm{ml}^{-1}$ epidermal growth factor (R\&D Systems), $30 \mu \mathrm{g} \mathrm{ml}^{-1}$ bovine pituitary extract (Invitrogen), 5\% FBS, $15 \mathrm{mM}$ HEPES and $0.01 \mu \mathrm{M}$ freshly added retinoic acid (Sigma) in a humidified incubator at $37^{\circ} \mathrm{C}$ with $5 \% \mathrm{CO}_{2}$.

Conditioned media and transwell assays. For competition-conditioned medium experiments, media were conditioned for $48 \mathrm{~h}$ by cultures of GFP-labelled $s c r i b^{K D}$ and wild-type cells with (competition condition) or without (mock condition) tetracycline. Recipient GFP-labelled $s c r i b^{K D}$ cells were pre-treated with tetracycline for $24 \mathrm{~h}$ and 10,000 cells per well were seeded into 24-well plates with $1 \mathrm{ml}$ of conditioned medium. For transwell assays, GFP-labelled scrib ${ }^{K D}$ cells $(10,000$ per well) were seeded at the bottom of a 24 -well plate. Co-cultures at a ratio of 1:10 $\left(\right.$ GFP-labelled $s c r i b^{K D}$ : wild-type or GFP-labelled $s c r i b^{K D}: s c r i b^{K D}$ ) were plated onto a transwell insert $(3.0 \mu \mathrm{m}$ pore size-polyester membrane, Corning) at 1,500 cells 
per insert). All $s c r i b^{K D}$ and GFP-labelled $s c r i b{ }^{K D}$ cells were pre-treated for $24 \mathrm{~h}$ with tetracycline before plating.

Fences system. Where applicable, immunofluorescence of cell competition was carried out in a 24-well plate using 'fences' (Aix Scientifics, http://www.aix-scientifics.co.uk/en/fences.html). The system allows two different populations of cells to be seeded on either side of a silicone barrier, thus allowing experimental and control conditions to be cultured, treated, imaged and (where applicable) stained within the same well/coverslip.

\section{Cell competition and contact-induced migration assays. Cell competition} assays on MDCK cells were carried out in 24-well plate fences. Control cultures were plated in the centre of the fence (1,000 cells per fence) at a ratio of 1:10 GFPlabelled $s c r i b^{K D}: s c r i b^{K D}$. Competition cultures were seeded on the outside of the barrier (8,000 cells per fence) at a ratio of 1:10, scrib ${ }^{K D}$ : wild-type cells. The fences were removed approximately $5 \mathrm{~h}$ after plating and the culture medium was replaced with or without addition of tetracycline. Twenty hours later, the culture medium was replaced with phenol red-free DMEM $(+10 \%$ FBS and $1 \%$ L-glutamine, Invitrogen) with or without tetracycline. Where specified, the chemical inhibitors were also added at this point, except for the ROCK, Piezo and S1P2 inhibitors, which were added after an additional $24 \mathrm{~h}$. Live imaging was started $2-4 \mathrm{~h}$ after the final media change and was continued for at least $50 \mathrm{~h}$ with regular media changes every $2-3$ days.

For cell migration assays, the cells were seeded as for competition assays, except that they were plated at a lower density (1,000 cells in the centre of the fence, $2,000-5,000$ cells in the outer chamber) and imaged more frequently (every $10 \mathrm{~min}$ to every $2 \mathrm{~h}$ ). Alternatively, where specified, cells for competition or migration assays were plated on gridded tissue culture plates ( $\mu$-Dish $35 \mathrm{~mm}$ Grid-500, Ibidi) at 6,250 cells per plate. This allowed us to find specific clones of cells for immunofluorescence analysis after live imaging had finished. Co-cultures, unless otherwise specified, were plated at a ratio of 1:10 ( $s c r i b^{K D}$ : wild-type).

The MTEC cells were plated in collagen-coated tissue culture inserts and allowed to grow for approximately 2 weeks until they reached homeostatic density before commencing experiments. In control cultures, wild-type (unlabelled) cells were plated with wild-type Rosa26R-Tomato (nuclear red) cells (MTEC Tomato) ${ }^{48}$ cells at a 2:1 ratio. In competition cultures, unlabelled p53-null cells (MTEC $p 53^{-1-}$ ) and wild-type Rosa26R-Tomato cells (MTEC Tomato) were plated at a 2:1 ratio. Nutlin-3 was added at $17.5 \mu \mathrm{M}$ on day 3 of live imaging. The medium was changed every 2 days.

Homeostatic cell density assays. These assays were carried out in 96-well plates. GFP-labelled $s c r i b^{K D}$ and $s c r i b^{K D} p 53^{-1-}$ cells $(8,000-12,000$ cells per plate) were pre-treated with tetracycline for $12 \mathrm{~h}$ before plating where applicable, in the presence or absence of inhibitors. Where applicable, Nutlin-3 was added $24 \mathrm{~h}$ after plating. The whole well was then imaged and the individual images were stitched together for further analysis to obtain data on total cell number and density. The plates were imaged every $6 \mathrm{~h}$ and cell culture medium and drug treatments were changed every 2 days.

Micropattern assays. For assays in micropatterns, GFP-labelled $s c r i b{ }^{K D}$ cells with or without tetracycline pre-treatment $(72 \mathrm{~h})$ were plated onto circular adhesive patterns $(\varnothing 800 \mu \mathrm{m})$ within a PEG cell-repellent surface ${ }^{26,61}$. The cells were flushed with culture medium $5 \mathrm{~h}$ after plating and the medium was replaced with phenol red-free DMEM ( $+10 \%$ FBS and $1 \%$ L-glutamine, Invitrogen) with or without tetracycline. Cell culture medium and drug treatments were changed every 2 days.

PDMS-based cell compression assays. The GFP-labelled $s c r i b{ }^{K D}$ cells were plated onto a stretched flexible silicone substrate (Gel pak PF-60-X4, $150 \mu \mathrm{m}$ thickness, Teltek), held in a custom-made chamber (GREM; http://www.jove.com/ video/51193/stretching-micropatterned-cells-on-a-pdms-membrane). Before plating, the clamped membranes were coated with $25 \mu \mathrm{g} \mathrm{ml}^{-1}$ fibronectin/PBS (Sigma) for $1 \mathrm{~h}$ at $37^{\circ} \mathrm{C}$. The membranes were stretched precisely by $2 \mathrm{~cm}$, which provided a $57 \%$ stretch over the resting length (unless otherwise specified). A PDMS rectangular chamber, with two compartments $(6.6 \times 13 \mathrm{~mm}$ each) was attached to the membrane with Baysilone paste (GE Bayer). Two densities (low and high) of tetracycline pre-treated or Nutlin-3 pre-treated ( $48 \mathrm{~h}$ ) GFP-labelled scrib ${ }^{K D}$ cells were plated, one in each compartment. High-density cells were plated between 75,000 and 120,000 cells per compartment, forming a confluent monolayer; low-density cells were plated at 25,000-35,000 cells per compartment. The cells were allowed to adhere for $24 \mathrm{~h}$ and then the membrane was released to induce compression. The cells were fixed in $4 \%$ PFA/PBS ( $3 \mathrm{~h}$ after release for $\mathrm{p} 53$ staining, $1.5 \mathrm{~h}$ for P-p38 staining and $5 \mathrm{~h}$ for cleaved Caspase- 3 staining) and processed for immunofluorescence. As per design, low- and high-density cells were stained and imaged from the same stretcher avoiding sample-to-sample variability. The p38 inhibitor was added one day before plating; the ROCK inhibitor was added $1 \mathrm{~h}$ before releasing the membrane.
E-cadherin-blocking experiments. To block E-cadherin-dependent junctions, $20 \mathrm{~h}$ after the addition of tetracycline, the cells were incubated in $10 \mathrm{mM}$ EDTA/ PBS for $5 \mathrm{~min}$, followed by a $20 \mathrm{~min}$ incubation in calcium-free DMEM (Invitrogen). The cells were then cultured in calcium-free DMEM $(+10 \%$ FBS and $1 \%$ L-glutamine, Invitrogen), supplemented with an anti-E-cadherin-blocking antibody (1:200; ref. 57). Live-image analysis was started $2-4 \mathrm{~h}$ after the final media change and continued for at least $50 \mathrm{~h}$

Immunofluorescence. For immunofluorescence, the cells were cultured on glass coverslips or on gridded dishes ( $\mu$-Dish $35 \mathrm{~mm}$ Grid-500, Ibidi). The cells were fixed for $10 \mathrm{~min}$ in $4 \%$ PFA/PBS, quenched for $10 \mathrm{~min}$ in $50 \mathrm{mM} \mathrm{NH}_{4} \mathrm{Cl} / \mathrm{PBS}$ and then permeabilized for $10 \mathrm{~min}$ with $0.1 \%$ Triton X-100/PBS. The cells were blocked in $2 \%$ BSA, $2 \%$ FBS/PBS for 30 min. Primary and secondary antibodies were diluted in blocking solution diluted 1:1 in PBS. The primary antibodies were incubated for a minimum of $1 \mathrm{~h}$ at RT, followed by washes in PBS; secondary antibodies were incubated for a minimum of $30 \mathrm{~min}$ at RT followed by washes in PBS. Coverslips were mounted with FluorSave (Millipore). For immunostaining against phosphorylated proteins, fixing solution was supplemented with PhosSTOP (1 tablet per $10 \mathrm{ml}$, Sigma), all PBS solutions were substituted with TBS, and blocking solution was substituted with 5\% BSA/TBS. For surface immunostaining, the cells were washed in ice-cold phenol red-free DMEM (Gibco) and incubated with primary antibody diluted in ice-cold phenol red-free DMEM at $4{ }^{\circ} \mathrm{C}$ for $45 \mathrm{~min}$. The cells were then washed in ice-cold PBS before fixation at RT in $4 \%$ PFA/PBS for $10 \mathrm{~min}$. Secondary antibody staining was then carried out as outlined previously.

Western blotting. The cells were lysed in $1 \%$ SDS/PBS and $10-20 \mu \mathrm{g}$ of protein was separated on a $4-12 \%$ gradient gel (Invitrogen) and transferred onto PVDF membrane for standard ECL blots (Anachem) or Immobilon FL PVDF for LI-COR blots (Millipore, $0.45 \mu \mathrm{m}$ pore size). The membranes were blocked with 5\% Marvel/ $0.05 \%$ Tween-20/PBS (PBST) for $1 \mathrm{~h}$ at RT, incubated in primary antibodies (in $2 \%$ Marvel/PBST) overnight at $4{ }^{\circ} \mathrm{C}$, washed in PBST and incubated in secondary HRP-conjugated antibodies for ECL blots or Infrared fluorescent dyes (IRDye$800 \mathrm{CW}$ and IRDye-680RD) for LI-COR blots, diluted in $2 \%$ Marvel/PBST for $1 \mathrm{~h}$ at RT. After washes in PBST, the membranes were developed using standard ECL (GE Healthcare) or scanned with a LI-COR Odyssey CLx near-infrared fluorescence imaging system. Quantifications for LI-COR blots were carried out using Image studio lite (http://www.licor.com/bio/products/software/image_studio_lite/ ?gclid=COWG_Yze98MCFYvpwgodfR8Adg), using Actin to normalize the samples for loading. For original full blots, see Supplementary Fig. 9.

RNA-seq and differential expression analysis. RNA-seq libraries were prepared with the TrueSeq RNA sample preparation V2 kit (Illumina) according to the manufacturer's instructions, and sequenced on an Illumina HiSeq 2000 instrument in single-read mode at 36 or 40 base length. The resulting fastq files were filtered for low-quality reads $(<\mathrm{Q} 20)$ and low-quality bases were trimmed from the ends of the reads $(<\mathrm{Q} 20)$.

Genome-based RNA-seq mapping was carried out using Canis lupus familiaris 3.1 (NCBI/Dog Sequencing Consortium) as a reference genome. Transcript sequences were assigned to genome using $\mathrm{BLAT}^{62}$. The resulting mappings were filtered by a mismatch threshold (2\%), as well as requiring $90 \%$ of the transcript to match the genome and all exons to match a single chromosome. This resulted in 21,571 transcripts mapping to the genome. This mapping was used as a junction file for Tophat 2 (ref. 63), which was used to map the RNA-seq reads to the genome. To provide gene names, transcript sequences were downloaded from the NCBI RefSeq database in March 2013 (24,538 sequences). Orthologues were found against the Mus musculus proteome (downloaded in January 2013-NCBI RefSeq) using Inparanoid ${ }^{64}$. The sequences were further annotated using InterProScan ${ }^{65}$ to provide both InterPro Domains and Panther ontology terms ${ }^{66}$. For differential expression, read counts were generated by quantifying overlaps with transcript locations. These were then used to generate RPKMs. Comparisons were made between pairs of conditions, each with at least four replicates. For a transcript to be included, counts per million had to be above 10 for all samples in at least one condition and within 2 -fold between replicates. Differentially expressed transcripts were then called using $\mathrm{EdgeR}^{67}$. Hits were selected applying the following thresholds: $P>0.05 \log$ FC (fold change) $>0.5$. Gene Ontology terms overrepresented among these lists were found using David Bioinformatics Resources ${ }^{68}$ in particular, KEGG pathway analysis.

Experiments in Drosophila wing discs. Flies were raised on a standard fly food containing yeast at $25{ }^{\circ} \mathrm{C}$. The larvae were collected at wandering third instar stage. Clones in wing discs were induced either with en-FLP (Supplementary Fig. 5a,b) or with hs-FLP (with a 10-min heat-shock at $37^{\circ} \mathrm{C}, 48-72 \mathrm{~h}$ before dissection; Supplementary Fig. 5c). For immunofluorescence, late third instar larvae were dissected in PBS followed by fixation in 4\% formaldehyde/PBS solution for $20 \mathrm{~min}$, permeabilization in $0.25 \%$ Triton X-100 PBS for 20 min and blocking in $4 \%$ FBS/ PBS for $30 \mathrm{~min}$. The primary and secondary antibodies were diluted in blocking solution. The primary antibodies were incubated overnight at $4{ }^{\circ} \mathrm{C}$, followed by washes in $0.25 \%$ Triton X-100/PBS; secondary antibodies were incubated for a 
minimum of $1 \mathrm{~h}$ at RT followed by washes in $0.25 \%$ Triton X-100/PBS. The wing discs were mounted in Vectashield (Vector Laboratories) and imaged on Leica SP5 or SP8 confocal microscopes. Optical sections were acquired with $0.8 \mu \mathrm{m}$ steps. The images were processed in ImageJ and Photoshop. Genotypes: Supplementary Fig. 5a,b en-flp, Act $>$ STOP $>$ Gal4, UAS-GFP/ + ; UAS-Scrib-RNAi, Supplementary Fig. 5c (left) hs-FLP, tub-Gal4, UAS-GFP/ +; + / +, FRT82, tubGal80/ FRT82, scrib2 and Supplementary Fig. 5c (right) hs-FLP, tub-Gal4, UASGFP/ + ; UAS-p53DN/ + , FRT82, tub-Gal80/ FRT82, scrib2. Antibodies used: anti-Scribble (1:2000, from Chris Doe lab), anti-E-Cadherin (DSHB DCAD2, 1:200). Both the antibodies were raised against Drosophila antigens and have been previously used in Drosophila.

Imaging and image analysis. Quantifications shown in the figures are from a single representative experiment of a minimum of three independent repeats per experiment, unless otherwise specified in the figure legend.

Fixed samples were imaged with a Leica SP5 or SP8 confocal microscope. For live imaging, the cells (kept at $37^{\circ} \mathrm{C}$ and $5 \% \mathrm{CO}_{2}$ ) were imaged using a Nikon BioStation CT with a $\times 10$ air objective with imaging frequency between every $10 \mathrm{~min}$ and every $6 \mathrm{~h}$ (as indicated in the movie time stamps), with media changes every 2-3 days. For each live imaging experiment, at least five fields were imaged by time lapse and analysed. Movie sequences or individual field time points that lost focus during the experiment were discarded from further analysis, as this precluded accurate cell counting.

For Fig. 1a-c and Supplementary Fig. 1d, quantifications of cell number over time were carried out using the open-source image analysis software Cell Profiler (http://www.cellprofiler.org/), using the nuclear GFP signal to segment cells.

To measure cell density in competition assays, the number of nuclei was manually counted using DAPI and/or nuclear GFP and divided by surface area, as calculated in Fiji (http://fiji.sc/Fiji; Fig. 1g and 2n, Fig. 5e, Supplementary Fig. 1e).

For Fig. 1k-n, cell number over time was quantified with the open-source image analysis software Icy ${ }^{69}$, using Icy Protocols. The nuclei were detected using the wavelet-based spot detection plugins. Areas with cysts, where nuclei were not visible due to overexposure or because they were out of focus, and areas without cells were excluded from both cell counting and from area measurements on a frame by frame basis. For Fig. 3h, Fig. 4c,k and Fig. 5b, entire wells of a 96-well plate were imaged by tiling. Individual images were then stitched and processed as above.

Cell height ( $\mu \mathrm{m}$, Fig. $1 \mathrm{~h}-\mathrm{j})$ was measured from apical to basal membranes using the open image analysis software Fiji.

Cell death in compression assays was quantified as the number of activated caspase-3 positive death events (Fig. 1o-q, Fig. 3i, Fig. 4d,l and Fig. 5c) divided by total number of DAPI-positive nuclei.

Kymographs were generated by first registering the hyperstack containing the different channels (bright-field, RFP and GFP) to remove any global motion or drift over time of the cells (Fig. 2d). The position of the centroid for each nucleus at each time point was extracted and the RFP and GFP channels were then projected on the same mean direction of motion by re-slicing the stacks and then projecting the maximum intensity of the centroid. For the control kymographs (GFP-labelled $s c r i b^{K D}$ : $s c r i b^{K D}$; RFP-labelled WT: WT), this was done only using the bright-field channel and one fluorescent channel.

The directionality index of migrating cells $(\mathrm{D}=$ Euclidean distance/total distance, Supplementary Fig. 2b,d) was calculated after manual tracking of individual cell nuclei ( $>40$ cells and $>5$ movies per condition) with the aid of ImageJ (http://imagej.nih.gov/ij/). Data analysis was performed with Matlab (MathWorks Inc.).

Analysis of cell shape and migratory features (Fig. $2 \mathrm{~g}-\mathrm{k}$ ). The aspect ratio, which is defined as the ratio of the long axis to the short axis of cells, was measured from three independent movies by manually fitting the best fit ellipses to single cells. To plot the distribution of angles between the cell's long axis and the cell's direction of motion, we determined for each cell the orientation of the cell's long axis and calculated its angular deviation with respect to the cell's direction of motion (data were binned at $40^{\circ}$ interval), by manual tracking. To measure the displacement of wild-type and scrib ${ }^{K D}$ cells, we carried out PIV analysis, using a custom algorithm based on the MatPIV software package for MATLAB, and measured the displacement of individual cells within the first row of contact. Trajectories across different movies were adjusted so that the first time point where both populations formed a broad interface and moved concertedly was set at $t=5 \mathrm{~h}$. Distance is the projected distance along the axis that joins both cell populations.

In Figs $3 \mathrm{c}-\mathrm{e}$ and $4 \mathrm{e}$, local density was measured for each cell by taking the sum of the Gaussian-weighted distances to all other cells within $50 \mu \mathrm{m}$ using a Gaussian function with $\sigma=20$.

Nuclear p53 (Fig. 3f,g), nuclear phospho-p38 (Fig. 4a,b,i,j) and nuclear p21 (Supplementary Fig. 4d) mean intensity was measured using Volocity (http:// www.perkinelmer.co.uk/pages/020/cellularimaging/products/volocity.xhtml), using DAPI as a mask to segment the nuclei.

For Fig. 5f-I, quantifications of cell number over time were carried out in ImageJ (http://imagej.nih.gov/ij/), using the nuclear Tomato signal to segment cells.
In Supplementary Fig. 2h-i, E-cadherin staining intensity was measured using Fiji. The individual cells were manually selected on an average $\mathrm{z}$ stack projection and their integrated density values were recorded.

Statistical analysis. No statistical methods were used to predetermine sample size. Every experimental condition and treatment was carried out alongside a complete control set of experiments or no treatment control. The sample size was chosen to see a statistical difference between data sets. In the few instances where no difference was observed, sample size was at least as big as in conditions that had shown a difference. The experiments were not randomized and there was no blinding during experiments or analysis, as samples were marked. We carried out a minimum of independent three repeats for each experiment, unless otherwise specified in the figure legend.

The $t$-Test was used in Supplementary Fig. 1e and Supplementary Fig. 2b,d, where data were normally distributed and with equal variance. The Wicoxon ranksum test was used in Supplementary Fig. 3f. Non-parametric Spearman correlation was used in Fig. 3e. Otherwise, the non-parametric KS test was used for all the statistical tests, removing the requirement for normally distributed data and equal variance. Throughout: ${ }^{\star} P<0.05,{ }^{\star *} P<0.005,{ }^{* *} P<0.0005$.

\section{References}

1. Morata, G. \& Ripoll, P. Minutes: mutants of drosophila autonomously affecting cell division rate. Dev. Biol. 42, 211-221 (1975).

2. Moreno, E. \& Basler, K. dMyc transforms cells into super-competitors. Cell 117, 117-129 (2004)

3. la Cova, de, C., Abril, M., Bellosta, P., Gallant, P. \& Johnston, L. A. Drosophila myc regulates organ size by inducing cell competition. Cell 117, 107-116 (2004).

4. Oertel, M., Menthena, A., Dabeva, M. D. \& Shafritz, D. A. Cell competition leads to a high level of normal liver reconstitution by transplanted fetal liver stem/progenitor cells. Gastroenterology 130, 507-520 (2006).

5. Rhiner, C. et al. Persistent competition among stem cells and their daughters in the Drosophila ovary germline niche. Development 136, 995-1006 (2009).

6. Sancho, M. et al. Competitive interactions eliminate unfit embryonic stem cells at the onset of differentiation. Dev. Cell 26, 19-30 (2013).

7. Clavería, C., Giovinazzo, G., Sierra, R. \& Torres, M. Myc-driven endogenous cell competition in the early mammalian embryo. Nature 500, 39-44 (2013).

8. Tamori, Y. \& Deng, W.-M. Tissue repair through cell competition and compensatory cellular hypertrophy in postmitotic epithelia. Dev. Cell 25, 350-363 (2013).

9. Martins, V. C. et al. Cell competition is a tumour suppressor mechanism in the thymus. Nature 509, 465-470 (2014).

10. Villa Del Campo, C., Clavería, C., Sierra, R. \& Torres, M. Cell competition promotes phenotypically silent cardiomyocyte replacement in the Mammalian heart. Cell Rep. 8, 1741-1751 (2014).

11. Rhiner, C. et al. Flower forms an extracellular code that reveals the fitness of a cell to its neighbors in Drosophila. Dev. Cell 18, 985-998 (2010).

12. Meyer, S. N. et al. An ancient defense system eliminates unfit cells from developing tissues during cell competition. Science 346, 1258236 (2014).

13. Merino, M. M. et al. Elimination of unfit cells maintains tissue health and prolongs lifespan. Cell 160, 461-476 (2015).

14. Levayer, R., Hauert, B. \& Moreno, E. Cell mixing induced by myc is required for competitive tissue invasion and destruction. Nature 524, 476-480 (2015).

15. Mamada, H., Sato, T., Ota, M. \& Sasaki, H. Cell competition in mouse NIH3T3 embryonic fibroblasts is controlled by the activity of Tead family proteins and Myc. J. Cell Sci. 128, 790-803 (2015).

16. Li, W. \& Baker, N. E. Engulfment is required for cell competition. Cell 129, 1215-1225 (2007).

17. de Beco, S., Ziosi, M. \& Johnston, L. A. New frontiers in cell competition. Dev Dyn. 241, 831-841 (2012).

18. Vivarelli, S., Wagstaff, L. \& Piddini, E. Cell wars: regulation of cell survival and proliferation by cell competition. Essays Biochem. 53, 69-82 (2012).

19. Vincent, J.-P., Fletcher, A. G. \& Baena-Lopez, L. A. Mechanisms and mechanics of cell competition in epithelia 14, 581-591 (Nature Publishing Group, 2013).

20. Baillon, L. \& Basler, K. Reflections on cell competition. Semin. Cell Dev. Biol. 32, 137-144 (2014).

21. Moreno, E. Cancer: Darwinian tumour suppression. Nature 509, 435-436 (2014).

22. Levayer, R. \& Moreno, E. Mechanisms of cell competition: themes and variations. J. Cell Biol. 200, 689-698 (2013).

23. Norman, M. et al. Loss of Scribble causes cell competition in mammalian cells J. Cell Sci. 125, 59-66 (2012).

24. Senoo-Matsuda, N. \& Johnston, L. A. Soluble factors mediate competitive and cooperative interactions between cells expressing different levels of Drosophila Myc. Proc. Natl Acad. Sci. USA 104, 18543-18548 (2007). 
25. Qin, Y., Capaldo, C., Gumbiner, B. M. \& Macara, I. G. The mammalian Scribble polarity protein regulates epithelial cell adhesion and migration through E-cadherin. J. Cell Biol. 171, 1061-1071 (2005).

26. Deforet, M., Hakim, V., Yevick, H. G., Duclos, G. \& Silberzan, P. Emergence of collective modes and tri-dimensional structures from epithelial confinement. Nat. Commun. 5, 3747 (2014).

27. Eisenhoffer, G. T. et al. Crowding induces live cell extrusion to maintain homeostatic cell numbers in epithelia. Nature 484, 546-549 (2012).

28. Marinari, E. et al. Live-cell delamination counterbalances epithelial growth to limit tissue overcrowding. Nature 484, 542-545 (2012).

29. Theveneau, E. et al. Chase-and-run between adjacent cell populations promotes directional collective migration 15, 763-772 (Nature Publishing Group, 2013).

30. Theveneau, E. \& Mayor, R. Cadherins in collective cell migration of mesenchymal cells. Curr. Opin. Cell Biol. 24, 677-684 (2012).

31. Lohia, M., Qin, Y. \& Macara, I. G. The Scribble polarity protein stabilizes E-cadherin/p120-catenin binding and blocks retrieval of E-cadherin to the Golgi. PLoS ONE 7, e51130 (2012).

32. Hogan, C. et al. Characterization of the interface between normal and transformed epithelial cells 11, 460-467 (Nature Publishing Group, 2009).

33. Zilfou, J. T. \& Lowe, S. W. Tumor suppressive functions of p53. Cold Spring Harb. Perspect. Biol. 1, a001883 (2009).

34. Brumby, A. M. \& Richardson, H. E. scribble mutants cooperate with oncogenic Ras or Notch to cause neoplastic overgrowth in Drosophila. EMBO J. 22, 5769-5779 (2003).

35. Igaki, T., Pagliarini, R. A. \& Xu, T. Loss of cell polarity drives tumor growth and invasion through JNK activation in Drosophila. Curr. Biol. 16, 1139-1146 (2006).

36. Igaki, T., Pastor-Pareja, J. C., Aonuma, H., Miura, M. \& Xu, T. Intrinsic tumor suppression and epithelial maintenance by endocytic activation of Eiger/TNF signaling in Drosophila. Dev. Cell 16, 458-465 (2009).

37. Ohsawa, S. et al. Elimination of oncogenic neighbors by JNK-mediated engulfment in Drosophila. Dev. Cell 20, 315-328 (2011).

38. Cuadrado, A. \& Nebreda, A. R. Mechanisms and functions of p38 MAPK signalling. Biochem. J. 429, 403-417 (2010).

39. Huang, C., Ma, W. Y., Maxiner, A., Sun, Y. \& Dong, Z. p38 kinase mediates UV-induced phosphorylation of p53 protein at serine 389. J. Biol. Chem. 274, 12229-12235 (1999).

40. Bulavin, D. V. et al. Phosphorylation of human p53 by p38 kinase coordinates $\mathrm{N}$-terminal phosphorylation and apoptosis in response to UV radiation. EMBO J. 18, 6845-6854 (1999).

41. Hofmann, M. et al. Mechanical pressure-induced phosphorylation of p38 mitogen-activated protein kinase in epithelial cells via Src and protein kinase C. Biochem. Biophys. Res. Commun. 316, 673-679 (2004).

42. Amano, M., Nakayama, M. \& Kaibuchi, K. Rho-kinase/ROCK: a key regulator of the cytoskeleton and cell polarity. Cytoskeleton 67, 545-554 (2010).

43. Wilkinson, S., Paterson, H. F. \& Marshall, C. J. Cdc42-MRCK and Rho-ROCK signalling cooperate in myosin phosphorylation and cell invasion. Nat. Cell Biol. 7, 255-261 (2005).

44. Nakagawa, K. et al. Cyclic compression-induced p38 activation and subsequent MMP13 expression requires Rho/ROCK activity in bovine cartilage explants. Inflamm. Res. 61, 1093-1100 (2012).

45. Rosenblatt, J., Raff, M. C. \& Cramer, L. P. An epithelial cell destined for apoptosis signals its neighbors to extrude it by an actin- and myosin-dependent mechanism. Curr. Biol. 11, 1847-1857 (2001)

46. Eisenhoffer, G. T. \& Rosenblatt, J. Bringing balance by force: live cell extrusion controls epithelial cell numbers. Trends Cell Biol. 23, 1-8 (2012).

47. Vassilev, L. T. et al. In vivo activation of the $\mathrm{p} 53$ pathway by small-molecule antagonists of MDM2. Science 303, 844-848 (2004).

48. Prigge, J. R. et al. Nuclear double-fluorescent reporter for in vivo and ex vivo analyses of biological transitions in mouse nuclei. Mamm. Genome 24, 389-399 (2013).

49. Shraiman, B. I. Mechanical feedback as a possible regulator of tissue growth. Proc. Natl Acad. Sci. USA 102, 3318-3323 (2005).

50. Yu, H., Mouw, J. K. \& Weaver, V. M. Forcing form and function: biomechanical regulation of tumor evolution. Trends Cell Biol. 21, 47-56 (2011).

51. Friedl, P. \& Alexander, S. Cancer invasion and the microenvironment: plasticity and reciprocity. Cell 147, 992-1009 (2011).

52. Muller, P. \& Vousden, K. H. Mutant p53 in cancer: new functions and therapeutic opportunities. Cancer Cell 25, 304-317 (2014).

53. Bilder, D. Cooperative regulation of cell polarity and growth by Drosophila tumor suppressors. Science 289, 113-116 (2000).

54. Zhan, L. et al. Deregulation of scribble promotes mammary tumorigenesis and reveals a role for cell polarity in carcinoma. Cell 135, 865-878 (2008).

55. Levayer, R., Dupont, C. \& Moreno, E. Tissue crowding induces caspasedependent competition for space. Curr. Biol. 26, 670-677 (2016).
56. Gumbiner, B. \& Simons, K. A functional assay for proteins involved in establishing an epithelial occluding barrier: identification of a uvomorulin-like polypeptide. J. Cell Biol. 102, 457-468 (1986).

57. Vestweber, D. \& Kemler, R. Rabbit antiserum against a purified surface glycoprotein decompacts mouse preimplantation embryos and reacts with specific adult tissues. Exp. Cell Res. 152, 169-178 (1984).

58. Ran, F. A. et al. Genome engineering using the CRISPR-Cas9 system. Nat. Protoc. 8, 2281-2308 (2013).

59. Adams, C. L. Mechanisms of epithelial cell-cell adhesion and cell compaction revealed by high-resolution tracking of E-cadherin-green fluorescent protein. J. Cell Biol. 142, 1105-1119 (1998).

60. You, Y., Richer, E. J., Huang, T. \& Brody, S. L. Growth and differentiation of mouse tracheal epithelial cells: selection of a proliferative population. Am. J. Physiol. Lung Cell Mol. Physiol. 283, L1315-L1321 (2002).

61. Tourovskaia, A., Barber, T., Wickes, B. T., Hirdes, D. \& Grin, B. Micropatterns of chemisorbed cell adhesion-repellent films using oxygen plasma etching and elastomeric masks. Langmuir 19, 4754-4764 (2003).

62. Kent, W. J. BLAT-the BLAST-like alignment tool. Genome Res. 12, 656-664 (2002).

63. Trapnell, C., Pachter, L. \& Salzberg, S. L. TopHat: discovering splice junctions with RNA-Seq. Bioinformatics 25, 1105-1111 (2009).

64. Alexeyenko, A., Tamas, I., Liu, G. \& Sonnhammer, E. L. L. Automatic clustering of orthologs and inparalogs shared by multiple proteomes. Bioinformatics 22, e9-e15 (2006).

65. Zdobnov, E. M. \& Apweiler, R. InterProScan-an integration platform for the signature-recognition methods in InterPro. Bioinformatics 17, 847-848 (2001).

66. Thomas, P. D. et al. PANTHER: a library of protein families and subfamilies indexed by function. Genome Res. 13, 2129-2141 (2003).

67. Robinson, M. D., McCarthy, D. J. \& Smyth, G. K. edgeR: a Bioconductor package for differential expression analysis of digital gene expression data. Bioinformatics 26, 139-140 (2010).

68. Huang, D. W., Sherman, B. T. \& Lempicki, R. A. Systematic and integrative analysis of large gene lists using DAVID bioinformatics resources. Nat. Protoc. 4, 44-57 (2008).

69. de Chaumont, F. et al. Icy: an open bioimage informatics platform for extended reproducible research. Nat. Methods 9, 690-696 (2012).

\section{Acknowledgements}

This work was supported by a Cancer Research UK Programme Grant (E.P. and L.W. A12460), a Royal Society University Research fellowship to E.P. (UF0905080), a Wellcome Trust PhD studentship to I.K., a Cambridge Cancer Centre PhD studentship to M.G., a European Research Council (ERC) grant to R.E.C.S. (243283-SYSGRO), a BBSRC grant (R.E.C.S. and A.C. BB/K006320/1) and Core grant funding from the Wellcome Trust (092096) and CRUK (C6946/A14492). The 'Biology-Inspired Physics at Mesoscales' group is a member of the IPGG Labex. The laboratoire PhysicoChimie Curie is member of the Labex CelTisPhyBio Labex. We thank: Yasuyuki Fujita for providing $s c r i b^{K D}$ and $E$-cad ${ }^{K D}$ MDCK cells and an E-cadherin shRNA construct; Richard Butler, Nicola Lawrence and Alex Sossick for help with microscopy and image analysis; Nicolas Carpi and Matthieu Piel for advice on the use of stretchers; James Nelson for E-cadherin constructs and discussions; Silvia Vivarell for cloning pGIPZ-GFP-NLS and pGIPZ-RFP-NLS and researchers cited in methods for reagents. We apologize to the researchers whose work could not be cited due to space limitations.

\section{Author contributions}

E.P. conceived and led the project. E.P. and LW designed the experimental strategy with help from RECS. M.G. characterized the role of ROCK and S1P2 and carried out assays in MTECs with help from E.L.R. M.G. and L.W. carried out the PDMS assays. K.K. carried out all cloning and, with help from M.G. and L.W., characterized the contribution of E-cadherin to contact-induced migration and loser status. M.G., C.R.B. and G.E.A. carried out RNAseq and data analyses. I.K. and L.W. carried out conditioned media and transwell experiments. I.K. carried out all Drosophila work. G.D. and P.S. generated micropatterns and analysed directional cell migration. A.C. and R.E.C.S. developed an algorithm for time-resolved cell density measurements of cell density. L.H.-O. and L.W characterized $s c r i b^{R E S}$ cells and p21 expression. All the other experiments were carried out by L.W. E.P. and L.W. prepared the manuscript with help from K.K., M.G., R.E.C.S. and other co-authors.

\section{Additional information}

Accession codes: The RNAseq data generated in this study have been deposited into the GEO (Gene Expression Omnibus) database under the accession code GSE79042.

Supplementary Information accompanies this paper at http://www.nature.com/ naturecommunications

Competing financial interests: The authors declare no competing financial interests. 
Reprints and permission information is available online at http://npg.nature.com/ reprintsandpermissions/

How to cite this article: Wagstaff, L. et al. Mechanical cell competition kills cells via induction of lethal p53 levels. Nat. Commun. 7:11373 doi: 10.1038/ncomms11373 (2016). (c) (i) This work is licensed under a Creative Commons Attribution 4.0 International License. The images or other third party material in this article are included in the article's Creative Commons license, unless indicated otherwise in the credit line; if the material is not included under the Creative Commons license, users will need to obtain permission from the license holder to reproduce the material. To view a copy of this license, visit http://creativecommons.org/licenses/by/4.0/ 